Original Research Paper

\title{
Sensing the Hydrogeomorphology and Palaeohydrologic Features of Mars Planet with Inference from the Egyptian Desert: An Insight from Satellite Images
}

\author{
Mohamed Yousif \\ Desert Research Centre, Department of Geology, P.O. Box 11753, El Matariya Cairo, Egypt
}

\author{
Article history \\ Received: 23-03-2020 \\ Revised: 10-04-2020 \\ Accepted: 23-04-2020 \\ Email: \\ yousif_mohamed80@daad- \\ alumni.de
}

\begin{abstract}
The water access in any planet of the universe can be considered a crucial evidence for life existence. The study of Mars has special importance where it has a complex preserved geological record of a time period longer than on Earth. Many regions of Mars planet are subjected to observations through the obtained satellite images in comparison to similar areas from the Earth (Egyptian deserts). The present study presents observations from the High Resolution Imaging Science Experiment (HiRISE) and Mars Orbiter Laser Altimeter (MOLA) colorized digital terrain model (DTM), indicate that many existed landforms could reveal the palaeohydrology of Mars. The regional structural lineaments (joints and/or faults) are extracted and mapped where the main trend is NE-SW. These lineaments are thought to be responsible with erosion processes about the origination of the drainage network of Mars. The hydrogeomorphology of Mars planet suggests past wetter conditions where the transition from wet to dry surface conditions is evidenced through a variations in the spatial distribution of drainage networks. It can be thought that the selected landforms in this study (drainages, deltas, gorges, paleo-lakes, paleo-channel), are revealing an ancient wet climates where precipitation was leading to surface runoff with main role of the tectonic influences existed on structural lineaments and rifts. The current study suggests two landing sites (Jazero delta and Eberswalde Delta) for the next Mars 2020 mission taking in consideration that these sites had potential of water resources that may be provide chances for past life existence until the microbial level.
\end{abstract}

Keywords: Palaeohydrology, Landforms, Geology, Remote Sensing, Mars, Egypt

\section{Introduction}

People around the world are wondering about the importance of Mars studies and why the space agencies are still sending many spaceflight to this planet and what motivates that many scientists are interested to study the Mars. The answer is simply that the Mars has a complex preserved geological record provide information about a time period longer than on Earth, where the Earth was irreversibly lost a lot of its geological history due to the past crustal recycling occurred through the terrestrial Plate Tectonics (Hamilton, 2007). An exogenic forces have been forming the Martian landforms and led to a variation of landscapes through the action of water, wind and ice (Rossi and Gasselt, 2010). However, the Mars landforms suggest a past wetter climate where the transition from wet to dry is evidenced by a change in the spatial distribution of drainage networks (Jacobsen, 2016). The largest drainage networks suggest a climatic conditions for fluvial runoff (Hynek and Phillips, 2003; Howard et al., 2005). It is observed that the younger craters are dissecting the drainage networks which suggest the valley networks were formed throughout the boundaries lying between the Noachian and Hesperian Epochs (about 3.7 Ga), (Howard et al., 2005; Fassett and Head, 2008). This event is followed by a changes in 
surface hydrology which evidenced by a reduction characters of the valley networks (size, number and distribution) during the Late Hesperian and Early Amazonian (about 3.0 Ga), (Fassett and Head, 2008; Hynek et al., 2010, Jacobsen, 2016). The history of hydrologic cycle of Mars can be obtained through paleodischarge analyses which can be considered as important factor to study the Mars science where it depends on a proxy for the past runoff, paleoclimate and evolution of landform models (Howard, 2007; Hoke et al., 2014). The paleodischarges can be estimated for the Mars fluvial features through the applications of empirical relationships related to the terrestrial-based (Jacobsen and Burr 2018), which express about relation between channel width to an calculate approximately of peak flow discharge (Irwin et al., 2005; Burr et al., 2010; Kite et al., 2015; Jacobsen and Burr, 2016). Nowadays, the most of water is existed on Mars in the form of ice or as vapor with small quantities in the atmosphere (Jakosky and Haberle, 1992). The water ice can be visible in one place where the north polar ices cap (Carr, 1996). The common water ice exists under the permanent carbon dioxide ice cap in the South Pole of Mars and also at the shallow depths underground at more temperate conditions (Bibring et al., 2004; ESA, 2004). Indeed, there are more than $21 \times 10^{6}$ cubic kilometers of ice have been recorded in the shallow surface of Mars which are sufficient to cover the whole Mars planet to a depth of $35 \mathrm{~m}$ (Christensen, 2006).

In the current research, many regions or localities of Mars planet are subjected to brief observations through the obtained satellite images (Fig. 1). These localities are selected carefully where they are containing landforms and deposits reveal the palaeohydrologic regime of Mars. Also, some localities of Earth are selected to show the same conditions recorded from Sahara deserts. This is representing a testing approach to employ the landforms and deposits to elucidate the palaeohydrologic setting of any area on Mars or Earth. The approach assumes that the paleo-pluvial periods had left many landforms and deposits resulted throughout the fluvial and water activities. The applied side of this approach is determined the areas that had been subjected to previous recharge and consequently can store water in subsurface as groundwater. The main objective of the current study is investigating the different landforms which reveal the palaeohydrologic regime of Mars in comparison with the same recorded features of Earth. The study can be considered as an attempt to learn about early Earth through the investigation of the older planet such as Mars. Mars can be considered a unique planet in the solar system where it provides information that thought to be really ever been Earth-like. Therefore, investigation of the palaeohydrologic regime has a significance importance to the Earth.

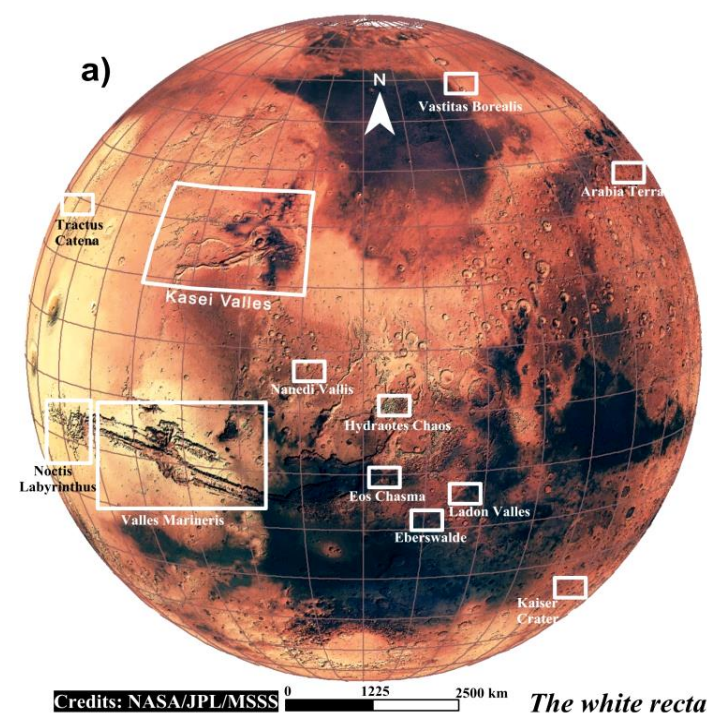

b)
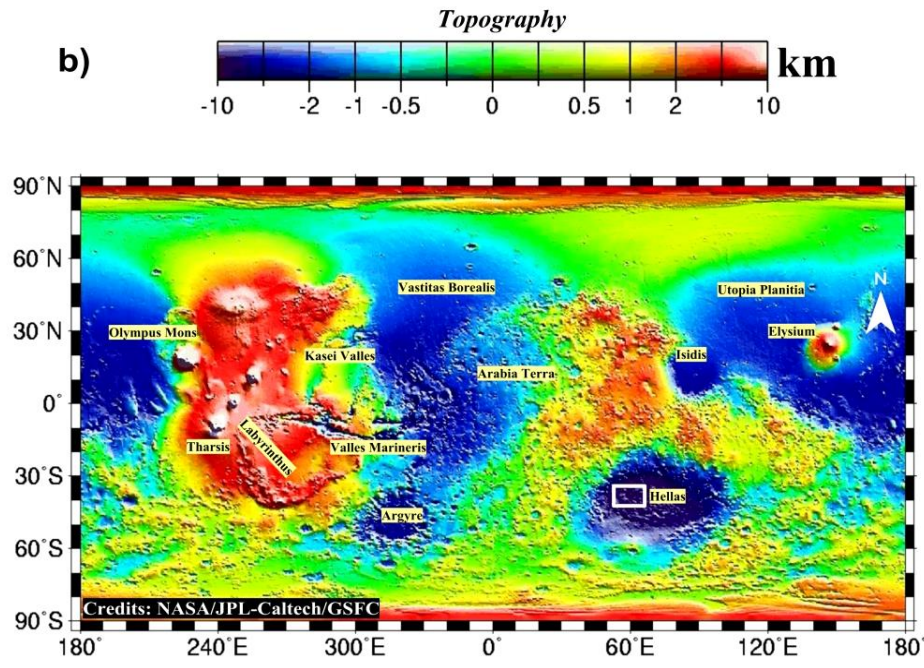

Credits: NASA/JPL/MSSS

Fig. 1: Key map of the investigated areas on Mars. (a) Three dimensional global view of Mars based on the Global Surveyor Orbiter Camera. (b) Global topography of Mars where blue color expresses about the low topography of the northern hemisphere (assumed to be the location of a primordial ocean that was includes liquid water, Brandenburg (1987). The white rectangular represents he investigated areas where the sites of these areas are determined using the Google Mars. The copyright note for these images and their interpretation: for images (1.a); Credits: NASA/JPL/MSSS and for image (1.b); Credits: NASA/JPLCaltech/GSFC 

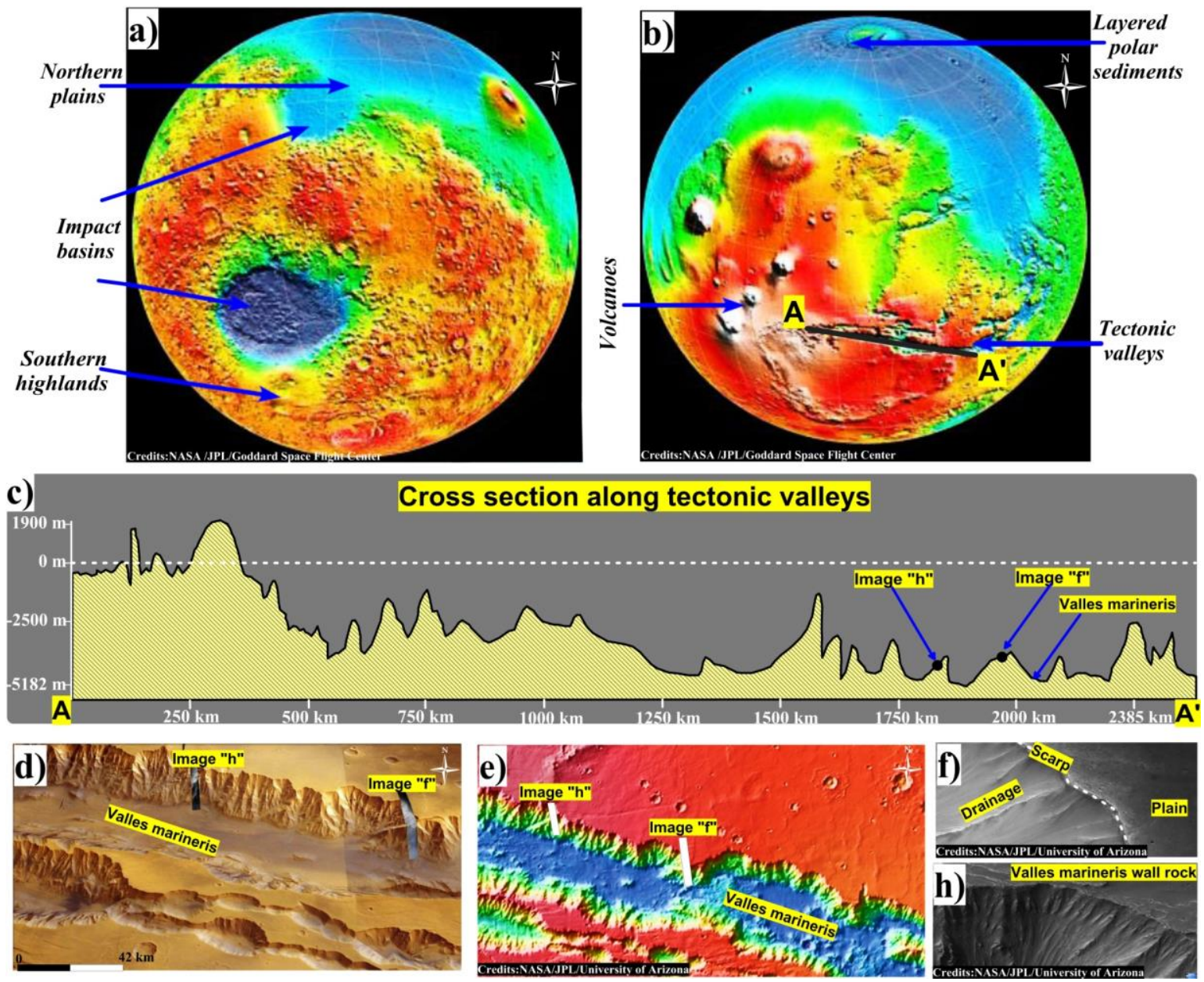

Fig. 2: General geomorphology of Mars from the Mars Orbiter Laser Altimeter (MOLA). (a) and (b) The false color images are showing Mars topography where blue areas illustrate elevation low regions, while red and white areas corresponding to high elevated regions of the planet (accessed from CRISM, 2019). (c) Cross section along the tectonic valleys showing the great variation elevations, created through Google Earth profile. d) Three dimensional views of the eastern portion of the tectonic valleys that called "Valles marineris". (e) Digital elevation model of the eastern portion of the tectonic valleys where blue color indicates low elevation and red color show the high elevation (NASA/JPL/University of Arizona). (f) The image shows eastern part of the Valles Marineris, where multi layers are existed on the slopes descending through the edges of the flat top rim composed from Lacustrine and/or Aeolian sediments and are resolved into a outcrop of size-scale boulders which reflect the high water energy (NASA/JPL/University of Arizona). (h) The image indicates a small portion of the northern wall of Valles Marineris (that is considers the largest canyon in the solar system). This canyon illustrates a view deep into the crust of Mars where A sequence of thin layers can be seen in the upper roughly $1000 \mathrm{~m}$ of the valley wall (NASA/JPL/University of Arizona). The two images ( $f$ and $h$ ) were captured through the High Resolution Imaging Science Experiment (HiRISE) camera on board NASA's Mars Reconnaissance Orbiter (MRO) spacecraft. The copyright note for these images and their interpretation: for images (2.a and 2.b); Credits: NASA/JPL/Goddard Space Flight Center, for images (2.e, 2.f and 2.h); Credits: NASA/JPL/University of Arizona

\section{General Geomorphology of Mars}

In spite of the fact that Mars imparts a few highlights in like manner to Earth, it is likewise altogether different. It has a few volcanoes like those on Earth. In any case, they are very colossal and would smaller person even the biggest ones here on Earth. Mars additionally has valleys and channels. A few researchers accept that these are the aftereffect of past water and geographical movement.
The outside of Mars is an incorporated record of the geographical procedures that have followed up on the planet over its history where the geomorphic landforms give proof to constructional occasions just as huge erosion scenes in Mars' history (NAS, 2003). By similarity with geomorphic includes on Earth, it has been resolved that volcanism, sway cratering, wind and water have been basic drivers of surface alteration and wide requirements have been put on the overall significance of 
these topographical procedures through time (NAS, 2003). The science and mineralogy of surface materials give extra imperatives on the idea of the procedures as well as on the physical conditions present on or close to the surface (e.g., temperature, $\mathrm{pH}$ and dampness). The main geomorphologic units such as; tectonic valleys, volcanoes, impact basins, northern plains and southern highlands, are illustrated in Fig. 2a and 2b. The created cross section along the tectonic valleys (Valles Marineris) illustrates the high rift affecting the topography of Mars where the difference in elevation reaches to $7 \mathrm{~km}$ along the main channel (Fig. 2c). This case is confirmed through the three dimensional views of the eastern portion of the Valles Marineris (Fig. 2d) and the digital elevation model where blue color indicates low elevation and red color show the high elevation (Fig. 2e). The two satellite images of this portion (Figs. $2 \mathrm{f}$ and $2 \mathrm{~h}$ ) illustrate that the slopes are descending through the edges of the flat top rim composed from lacustrine sediments and also indicates a small portion of the northern wall of Valles Marineris has a view deep into the crust of Mars (images were captured through the High Resolution Imaging Science Experiment "HiRISE" camera on board NASA's Mars Reconnaissance Orbiter "MRO” spacecraft).
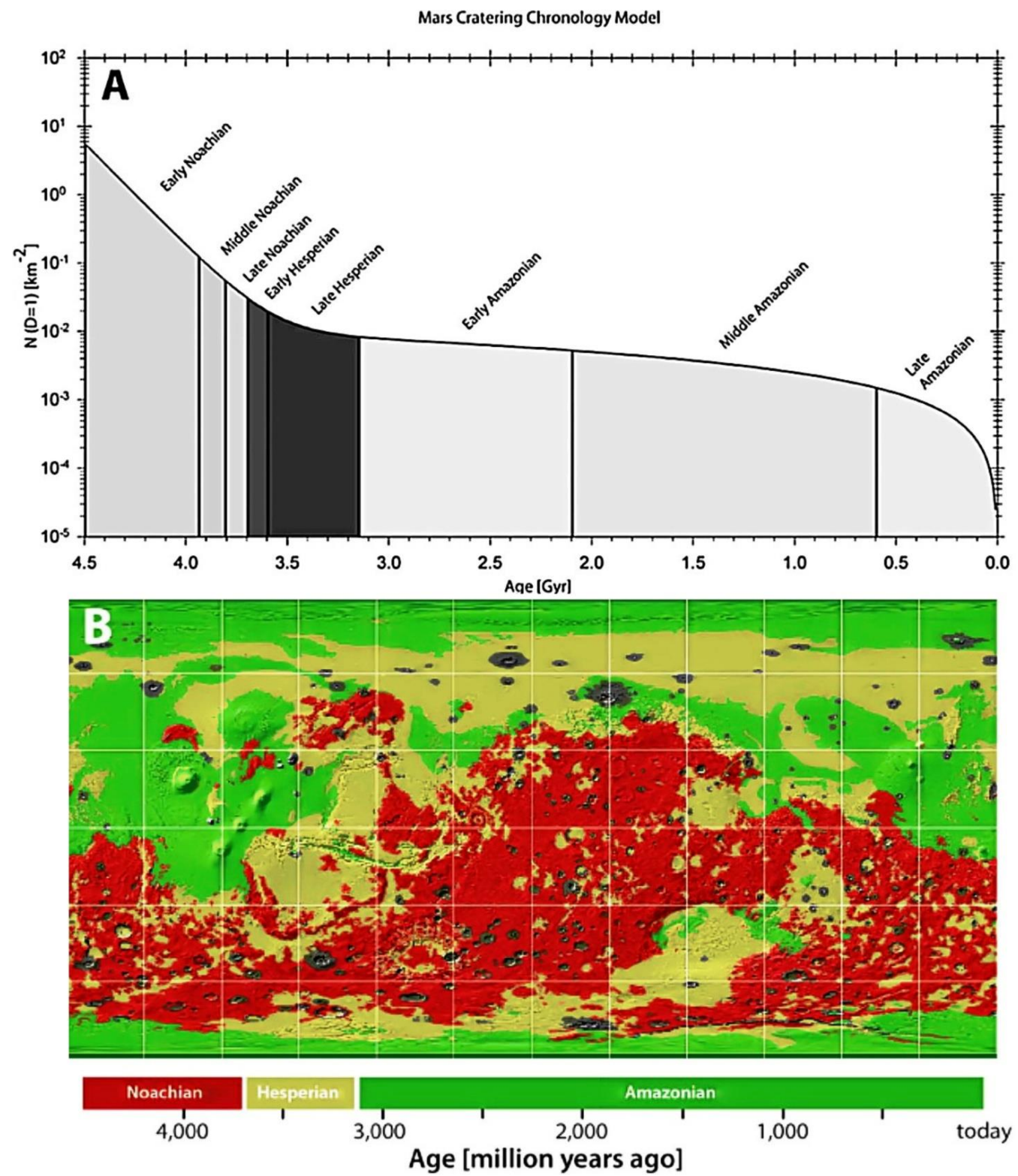

Fig. 3: (a) Chronology model of Mars planet with indicated Martian eras (Hartmann and Neukum, 2001; Rossi and van Gasselt, 2010). (b) Geological map of Mars, illustration the three eras on this planet: Noachian (4.65 to $3.7 \mathrm{Gyr}$ ), Hesperian (3.7 to $3.0 \mathrm{Gyr}$ ) and Amazonian (3.0 Gyr till the present), (Scott and Tanaka, 1986; Greeley and Guest, 1987; Rossi and van Gasselt, 2010) 


\section{General Geology of Mars}

The learning on Martian Geology has hugely expanded in last 40 years where several missions circling or meandering Mars altered our comprehension of its advancement and topographical highlights, in a few different ways like Earth (Rossi and van Gasselt, 2010). The subdivision of the stratigraphic arrangement of Mars depends on marker skylines that are framed by fields shaping volcanism (Scott and Carr, 1978; Tanaka, 1986; Tanaka et al., 1992). Martian geologic timeframes are from most established to most youthful: The Noachian, the Hesperian and the Amazonian and subdivisions into ages (Scott and Carr, 1978; Tanaka, 1986; Tanaka et al., 1992). For Mars, a few order models were proposed and changed throughout the accessibility of new higher goals information (Rossi and van Gasselt, 2010). A portion of these endeavors have been joined of late to shape the right now ongoing order model by Hartmann and Neukum (2001). Stratigraphic (limits of timeframes) are marginally unique which has prompted a Hartmann Model (HM) and a Neukum Model (NM). The brief geologic setting was achieved by (Rossi and van Gasselt, 2010), as following (Figs. 3a and 3b):

- A Pre-Noachian period is casually settled in spite of the fact that the Noachian premise isn't uncovered; be that as it may, radiometrically determined ages for the Martian shooting star ALH84001 with a crystallization time of $4.5 \mathrm{Gyr}$ fits into this period (Mittlefehldt, 1994)

- The Noachian Period is described by the oldest, thickly cratered units in the good countries covering a period scope of more seasoned than 3.97 Gyr back to 3.74 Gyr prior (Tanaka et al., 1992; Hartmann and Neukum, 2001)

- The Hesperian Period is subdivided into the Early and Late Hesperian ages spreading over $3.74 \mathrm{Gyr}$ to $2.9 \mathrm{Gyr}$ prior and is described by the Hesperia Planum

- The Amazonian time frame traverses quite a bit of Martian history and starts 2.9 Gyr back as indicated by the Hartmann model (HM) and up to $3.31 \mathrm{Gyr}$ prior as indicated by the Neukum order model (NM). The period is for the most part characterized through procedures identified with the northern swamp units and fields materials and is described by broad reemerging forms

\section{Data Sources and Methods}

The current research is based on satellite images which obtained from different space agencies. Therefore, the credits of each image is added at the bottom of each image and also mentioned in the caption to illustrate the rights. The main agencies which have the credits of the used images are, National Aeronautics and Space Administration (NASA, USA), Deutsches Zentrum für Luft- und Raumfahrt (DLR, German Aerospace Center), the European Space Agency (ESA) and the Arizona State University (USA). The satellite images were produced through the following:

1) Global Surveyor Orbiter Camera (NASA/JPL/MSSS)

2) The Mars Orbiter Laser Altimeter (MOLA), (NASA/JPL/University of Arizona)

3) High Resolution Imaging Science Experiment (HiRISE) camera on board NASA's Mars Reconnaissance Orbiter (MRO) spacecraft (NASA/JPL/University of Arizona)

4) Digital elevation model (DEM) of the eastern portion of Mars' Valles Marineris, (ESA/DLR/FU Berlin, G. Neukum)

5) The Mars Global Surveyor throughout 2003 (NASA/JPL/Malin Space Science Systems)

6) The stereo and color channels of (HRSC) on board ESA's Mars Express spacecraft (DLR, ESA and FU Berlin, the Mars Express HRSC images are published under a creative commons license since Dec. 2014 (ESA/DLR/FU Berlin, CC BYSA 3.0 IGO)

7) Google Mars pro. Images are used to create an elevation profile for different locations and also for 3D views, where the Mars satellite images are obtained through the option of switch between Mars and Earth. The credits for these images are to: Image/NASA/USGS and ESA/DLR/FU Berlin (G. Neukum).

Consequently, the visual interpretation represents the main tool that is applied for obtained satellite images. Also, some features are extracted and illustrated through the investigation of the Multi-orbit Digital Terrain Models (DTM) derived from multiple stereo image strips of the High-Resolution Stereo Camera (HRSC) of ESA's Mars Express (HRCS web GIS, FUB/DLR/ESA). This DTM is used for extraction of the inferred faults and/or fractures (structural lineaments). Consequently, the visual interpretation represents the main tool that is applied for obtained satellite images. Also, some features are extracted and illustrated through the investigation of the Multi-orbit Digital Terrain Models (DTM) derived from multiple stereo image strips of the High-Resolution Stereo Camera (HRSC) of ESA's Mars Express (HRCS web GIS, FUB/DLR/ESA). This DTM is used for extraction of the inferred faults and/or fractures (structural lineaments). The Global Mapper 10, Arc GIS ver. 10.4 and Surfer 13 are the main used software in the current study to produce maps, cross sections and $3 \mathrm{D}$ visual views. 


\section{Results}

\section{Structural Lineaments}

The visual interpretation of the digital terrain model of Mars reveals that there are many faults affecting the surface of Mars. The difference in elevation can reach to $10 \mathrm{~km}$ like the case reported in the canyon of Valles Mariner is (Figs. 4a, 4b and 9a). The extracted structural lineaments are corresponding to the main rifts in the Tharsis region of Mars which recorded through the works of Hauber et al. (2010). These rifts are differentiated in their trends and their influences. It's noted that the structural lineaments (faults and/or fractures) are associated with these rifts (Fig. 4a) where the main trend is NE-SW and NW-SE. The extracted lineaments (Fig. 4b) are based on the distributions of volcanoes and the difference in elevation. Also, the visual interpretations of the Mars Orbiter Laser Altimeter (MOLA) global elevation model hill-shade for five areas (Fig. 5a-5f) clarify the minor and major fractures appear on the surface and affecting the rock exposures. It's thought that the drainage network of the Mars is controlled by the fractures systems as it happen on the Earth where the water are usually flows along the weakest path.

\section{Hydrogeomorphologic and Palaeohydrologic Features}

\section{Drainage Network}

The drainage or valley networks are the most important evidence in favor of a radically different climate on early Mars. Like many drainage systems on Earth, Martian valley networks can be dendritic (branching) with many tributaries that begin near the peaks of topographic divides. This geomorphologic feature suggests an origin resulted from a hydrological cycle driven by precipitation (rain or ice). In the present study, the drainage networks of Mars are subdivided into two categories according to their origin; the first is the drainage was resulted through melting of ice on the crater rim (Fig. 6), the second that was originated through the action of precipitation where a dendritic drainage network is developed (Fig. 7). For both types, the low drainage ratios with a large number of open crater lakes can provide indications about high precipitation rates associated with a wet climate (Fassett and Head, 2008). This condition is recorded in Arabia Terra and north of Hellas (Fig. 11) where the open-basin lake drainage ratios are varying with location and with wetter formation conditions (Fassett and Head, 2008).

In the current study, the first drainage category is investigated in the crater of Noachis (Fig. 6a) where numerous valley networks can be seen on the inner rim and indicates the presence of ice in the subsurface. This drainage is mainly short representing amphitheaterheaded tributaries that were formed along the major escarpments and on the slopes of volcanic cones. The image of the gullies and concentric Fill in an Unnamed Rampart Crater in Noachis Terra shows about $14 \mathrm{~km}$ across of a crater in Noachis Terra where these gullies in its walls indicate the existence of ice and water throughout its history. The illustrated pattern on the image indicates that ice-rich or water-rich materials were excavated at the time of impact (Fig. 6e). Based on this theory, the rocks of this crater are mixed with water; therefore they are flowed easily along the surface through the drainage (NASA/JPL/University of Arizona).
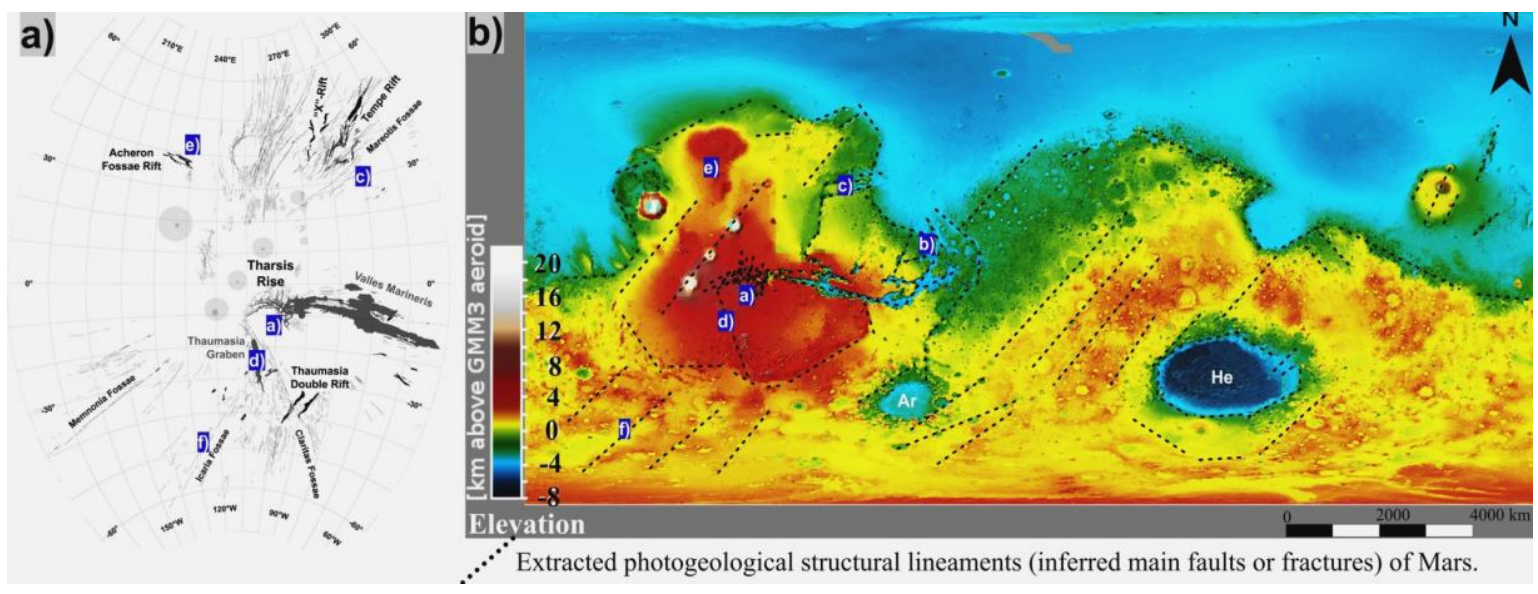

Fig. 4: (a) The main rifts in the Tharsis region of Mars, in stereographic projection (Hauber et al., 2010). (b) Multi-orbit digital terrain models (DTM) derived from multiple stereo image strips of the High-Resolution Stereo Camera (HRSC) of ESA's Mars Express (HRCS web GIS, FUB/DLR/ESA) that used for extraction of the inferred faults and/or fractures (illustrated by the dashed lines). These lineaments represent the extensional structures of Mars. The DTM product has been hill-shaded and colour-coded by Freie University of Berlin. The white letters with blue background (a to f) are showing the locations for some investigated areas discussed in Fig. 5 

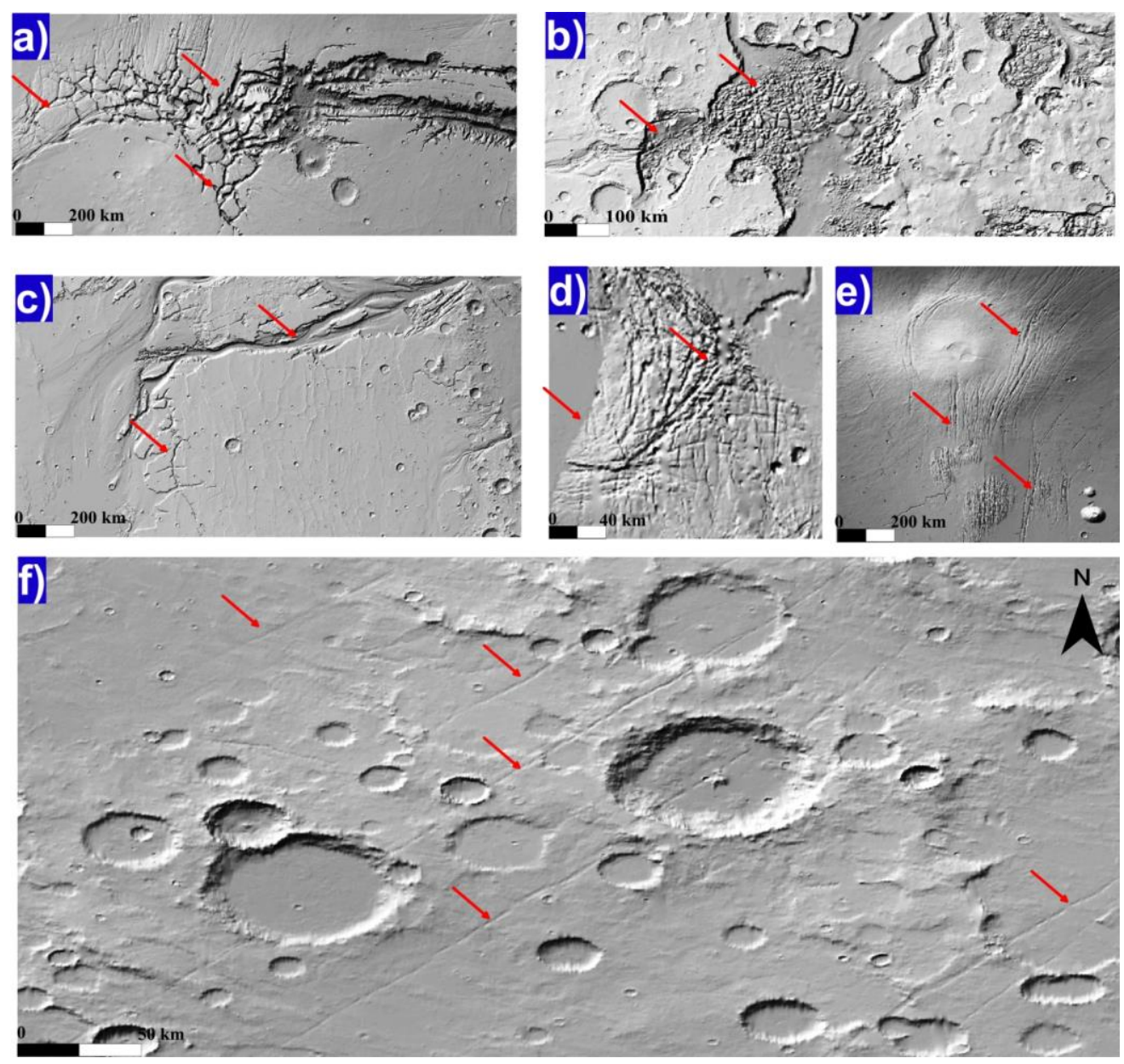

Fig. 5: Local fractures and/or faults affecting the surface of Mars planet illustrated through the MOLA (Mars Orbiter Laser Altimeter) global elevation model, grayscale hill-shade (HRCS web GIS, FUB/DLR/ESA). The locations of these sites are shown in figure 4 . The five images clarify the minor and major fractures appear on the surface and affecting the rock exposures. The red arrows refer to the inferred structural lineaments.

Also, this type of drainage is recorded along the edge of the Kaiser crater that thought to be formed throughout the rainy seasons (Fig. 6c). The obtained image (NASA/JPL/University of Arizona) clarifies that the gullies along the wall of Kaiser crater where the drainage (dark black color) indicating the presence of water resulting from ice melting and flows to the floor of the crater (Fig. 6f). This feature is like the drainage network along the edge of Sin El Kadab plateau (Fig. 6g) of Western Desert of Egypt where their formation is thought to be resulted from heavy precipitation during the past pluvial times and/or through the action of groundwater sapping. If it was originated by the groundwater sapping, this means that water was flowing from the Earth under pressure to the surface with a huge amount and causes the formation of these drainages. This can be also a hypothesis to the drainage appears in image (Fig. 6f) which need more investigation. On the other hand, the digital terrain model (Fig. 6h) of Hephaestus
Fossae (ESA's Mars Express orbiter, ESA/DLR/FU Berlin, G. Neukum) provides an indication of the planet watery past where a long channel with their tributaries are flowing for about $80 \mathrm{~km}$ distance, from the crater in the south to the low elevation areas in the north. The second type of the drainage network that was recorded on Mars is the dendritic drainage network of dried-up valleys. It was noted to the east of Huygens crater (north of Hellas), (Fig. 7a, the image from ESA's Mars express, 2018 during Mars Express orbit). The valley networks which show distinctly dendritic tributary patterns are thought to be formed during heavy precipitation events. This assumption is based on the investigation of the dendritic type on the Earth, such as the case of Wadi Qena basin (Egypt, Fig. 7d). In addition, the structural lineaments that affect the surface of Mars can play an important role in the origin of the dendritic drainage network, where the surface water flows along the fracture systems forming a branched form. 

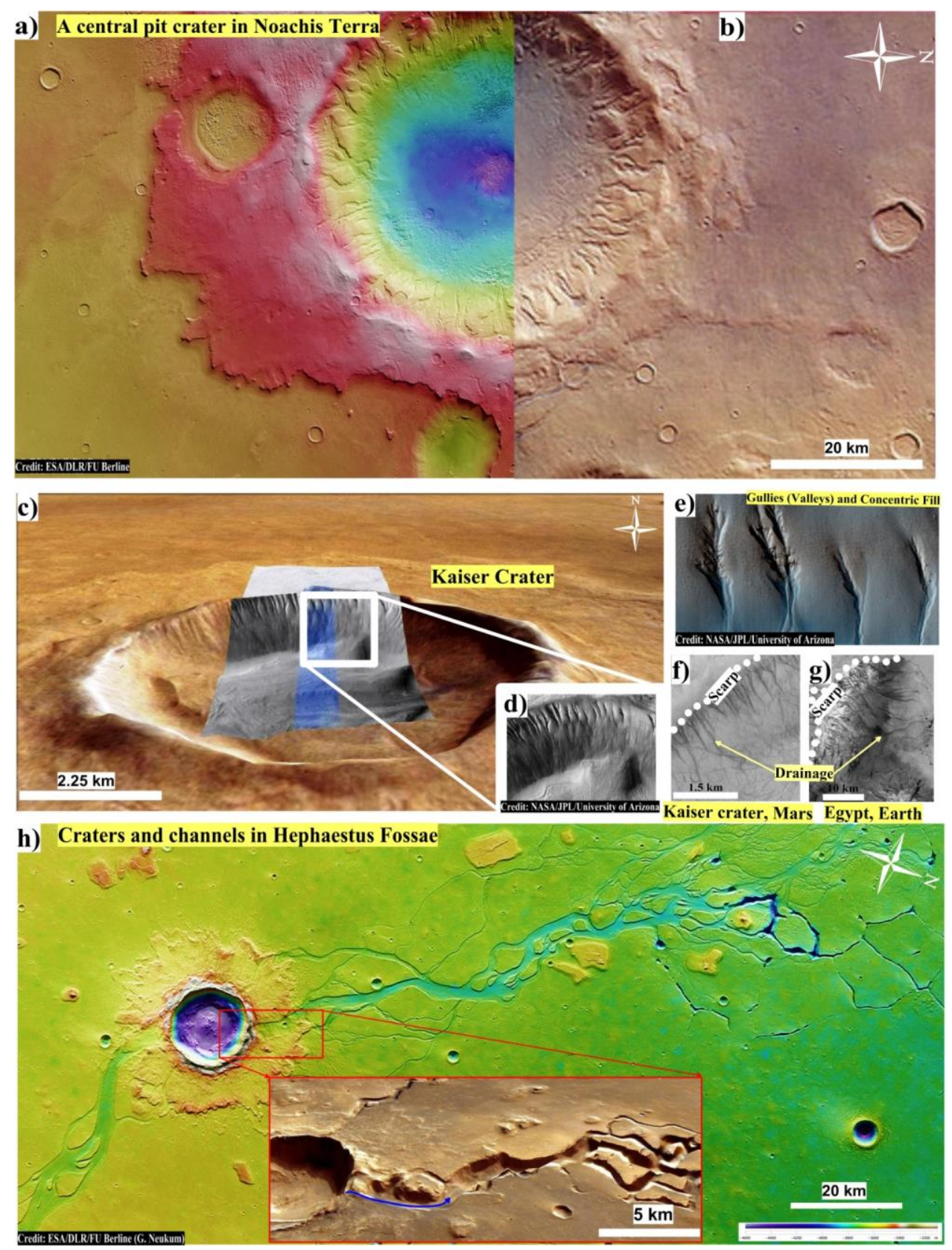

Fig. 6: (a) The crater in Noachis Terra (located in the southern highlands of Mars, west of impact basin Hellas Planitia) shows a central depression and drainage valleys at the crater rim where numerous valley networks can be seen on the inner rim. These indicate the presence of ice in the subsurface. This image was created by the group of Planetary Sciences and Remote Sensing group in Freie Universität, Berlin. (b) Oblique perspective view obtained using data from the HRSC stereo channel of the same area (right side) where the anaglyph provides a three-dimensional view of the landscape. (c) Three dimensional view of Google Earth showing the location of the investigated crater. (d) Drainage network along the edge of the crater that thought to be formed throughout the rainy seasons. (e) Gullies and Concentric Fill in an Unnamed Rampart Crater in Noachis Terra. The image shows about $14 \mathrm{~km}$ across of a crater in Noachis Terra where the gullies in its walls indicate the existence of ice and water throughout its history. (f) The image shows the gullies along the wall of an ancient Kaiser crater where the image covers an area of 3 kilometers across. (g) Drainage network along the edge of Sin El Kadab plateau of Western Desert, El Kubanyia basin, Egypt. (h) Craters and channels in Hephaestus Fossae (imaged by the high-resolution stereo camera on ESA's Mars Express orbiter on 28 December 2007). The image indicates the elevation of the terrain (the green and yellow colors represent shallow ground, blue and purple stand for deep depressions). The noted channel network can be considered as indicative of the Planet watery past. The copyright note for image (6.a, 6.b and 6.h) is: Credits: ESA/DLR/FU Berlin (G. Neukum), CC BY-SA 3.0 IGO, while for images (6.d, 6.e and 6.f) and their interpretation; Credits: NASA/JPL/University of Arizona 


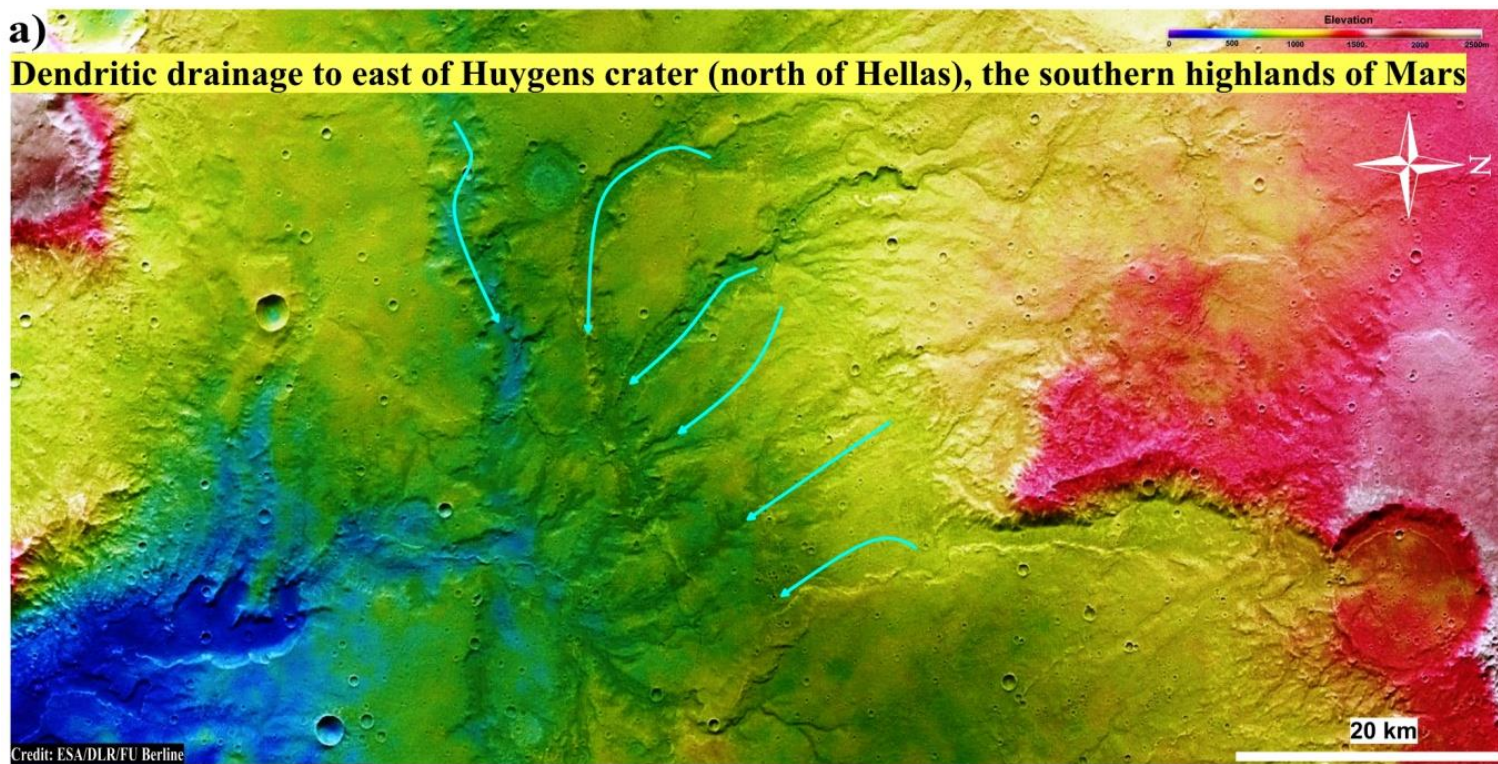

b)Youthful channels in one of Mars crater

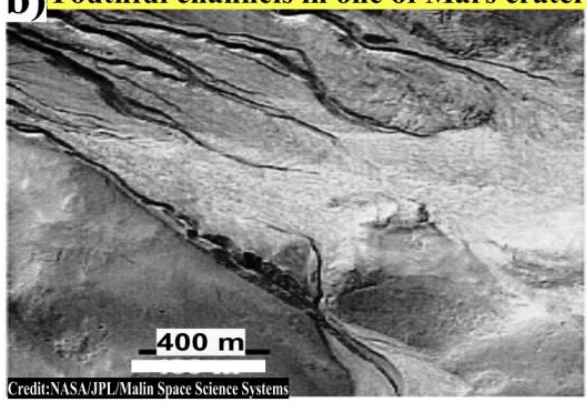

c) Valley networks in the Thaumasia region.

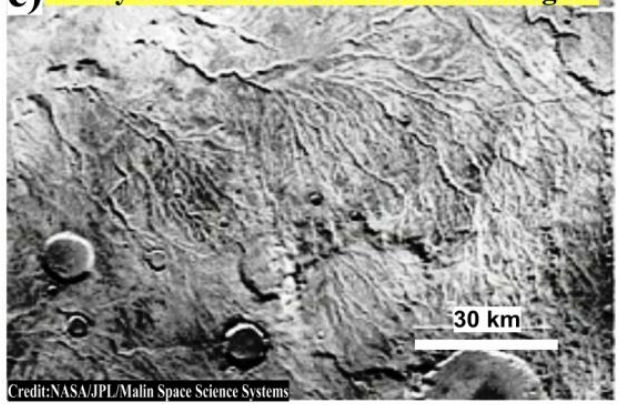

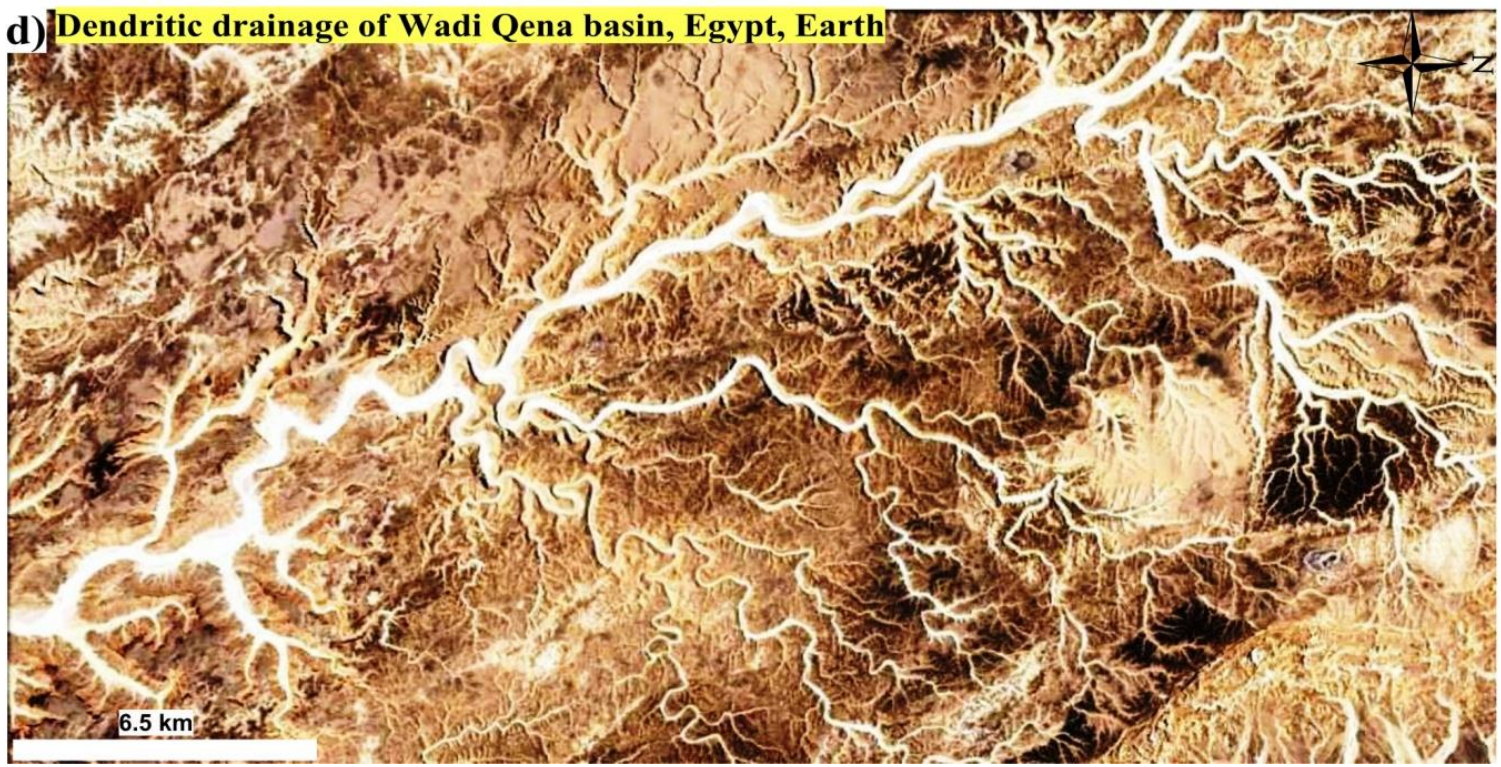

Fig. 7: (a) Dendritic drainage network of dried-up valleys on Mars, to east of Huygens crater (north of Hellas), (the image from ESA's Mars Express, on 19 November 2018 during Mars Express orbit, with ground resolution about $14 \mathrm{~m} /$ pixel, image is centered at $66^{\circ} \mathrm{E} / 17^{\circ} \mathrm{S}$ ). (b) Youthful channels in one of Mars crater (centered at: $37^{\circ} \mathrm{S}, 168^{\circ} \mathrm{W}$ ). (c) Valley networks in the Thaumasia region (centered at: $42^{\circ} \mathrm{S}, 93^{\circ} \mathrm{W}$ ). (d) Dendritic drainage of Wadi Qena basin, Egypt, Earth (Google Earth Tm). The copyright note for image (7.a, 7.b and 7.c) is: Credits: NASA/JPL/Malin Space Science Systems. 

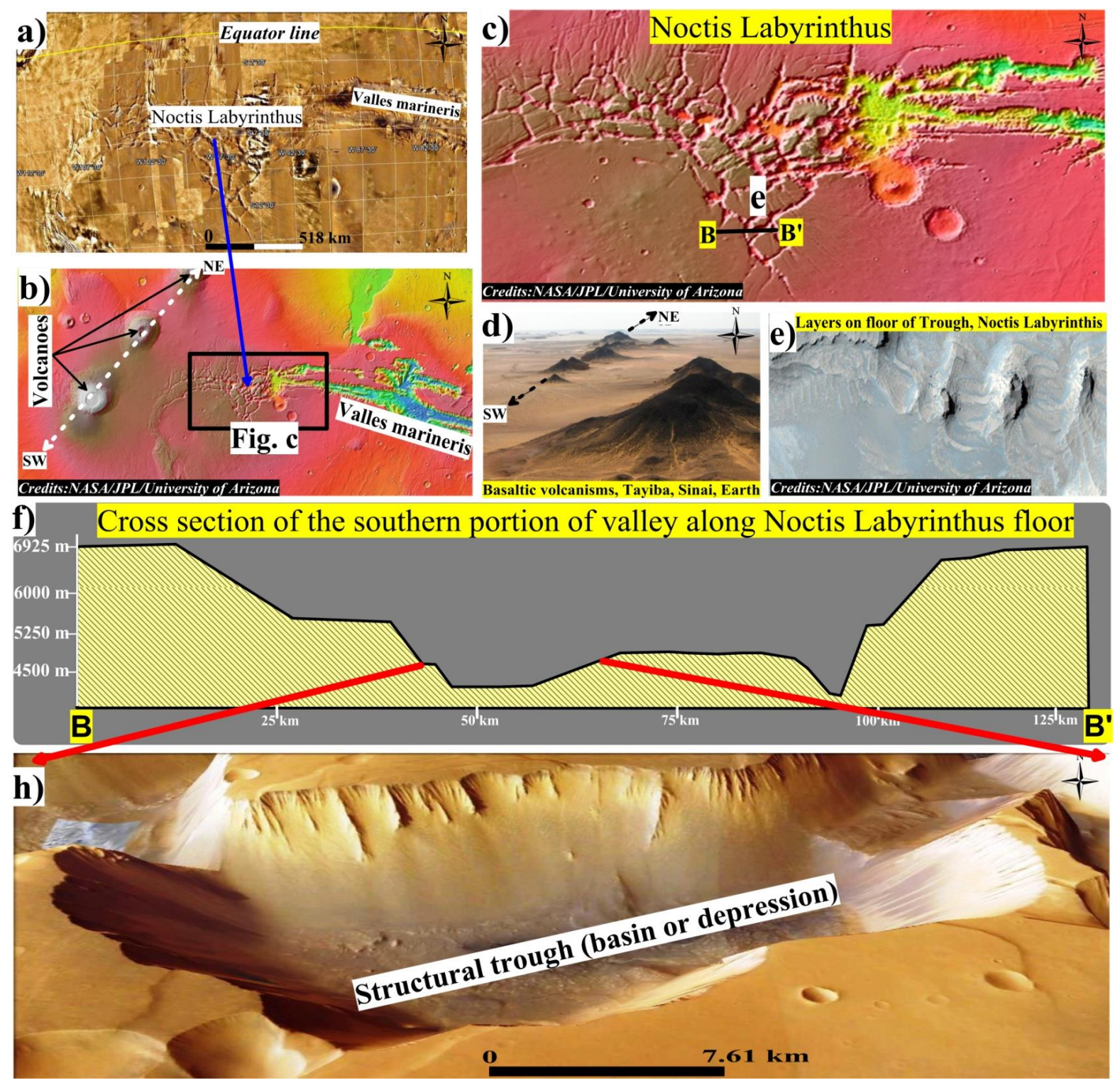

Fig. 8: Features of Noctis Labyrinthis. (a) Google Earth image indicates the location of Noctis Labyrinthis. (b) and (c) Digital elevation model of the area and its vicinities (NASA/JPL/University of Arizona). The two images (b and c) illustrate the dense fractures affecting the surface layers of Noctis Labyrinthis. (d) Field photo of basalt flow in Sinai (Egypt, Earth) in the northern portion of Suez Gulf. This basaltic volcanism is associated with the rift initiation in the northern Red Sea rift system (Bosworth, 2015). (e) Layers of Noctis Labyrinthis along the floor of a trough. (f) Cross section B-B' along the southern portion of Noctis Labyrinthis. (h) Three dimensional view (Google Earth) illustrates the trough floor. The copyright note for these images and their interpretation: for images (8.b, 8.c and 8.e); Credits: NASA/JPL/University of Arizona

\section{Features from Noctis Labyrinthis and Valles Marineris}

In the present study, two wide areas are investigated to clarify the associated factors that contributed in the formation of the most distinguished landforms of Mars planet. The landforms of Noctis Labyrinthis (Fig. 8) are expected to be resulted through the geological structures followed by water action along these fractures. The digital terrain model
(NASA/JPL/University of Arizona, Figs. 8b and 8c) of this area shows dense fractures sets affecting the surface exposures where Noctis Labyrinthis contains many troughs (basins and depressions) that are structurally controlled. It's thought that this structure is related to the nearby volcanoes that have a trend NESW. These volcanoes are like the recorded ones on Earth (Wadi Tayiba, Sinai, Egypt) as it was indicated in Fig. 8d. The volcanoes to the west of Noctis Labyrinthis show a NE-SW trend. These volcanoes 
may be contributed to the existed dense fractures system in that area. The layers of Noctis Labyrinthis (Fig. 8e) appear along the floor of a trough which shows faults extending across western portion of Valles Marineris. The uplift of the Plateau led to extension in this region and along with water drainage may explain the trough formation. The drawn cross section B-B' and the three dimensional view (Figs. $8 \mathrm{f}$ and $8 \mathrm{~h}$ ) along the southern portion of Noctis Labyrinthis shows the difference in elevation reaches to $3 \mathrm{~km}$ that support the hypothesis that this landform is resulted from structural influence followed by water action.

These regional structures (fractures and trough/faults) of Noctis Labyrinthis may be extended to the west and associated with the huge canyon of Mars called "Valles
Marineris" (Fig. 9a). The three dimensional view of the eastern portion of Valles Marineris (created through the digital terrain model, ESA/DLR/FU Berlin) indicates that it may be represented one of the great rift above Mars. The canyon of Valles Marineris has more than $4000 \mathrm{~km}$ long, with $200 \mathrm{~km}$ wide and approximately 10 $\mathrm{km}$ deep. This deep valley is thought to be resulting from a huge rift followed by an extreme surface water action. This distinguished rift may be occurred during the formation of the adjacent Tharsis volcanic region, (Olympus Mons, the largest volcano of the Solar System). This rift can be compared with the Gulf of Suez rift (Fig. 9b) which extends in Egypt and separate between the Eastern Egyptian Desert and Sinai Peninsula (Laak and Sheneshen, 2012).
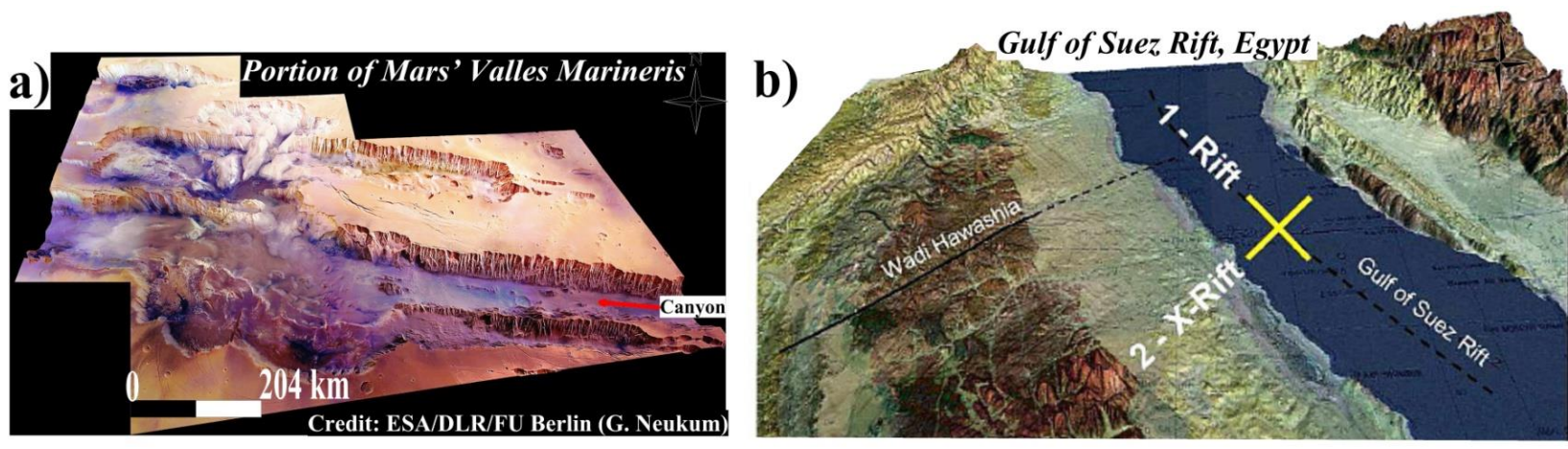

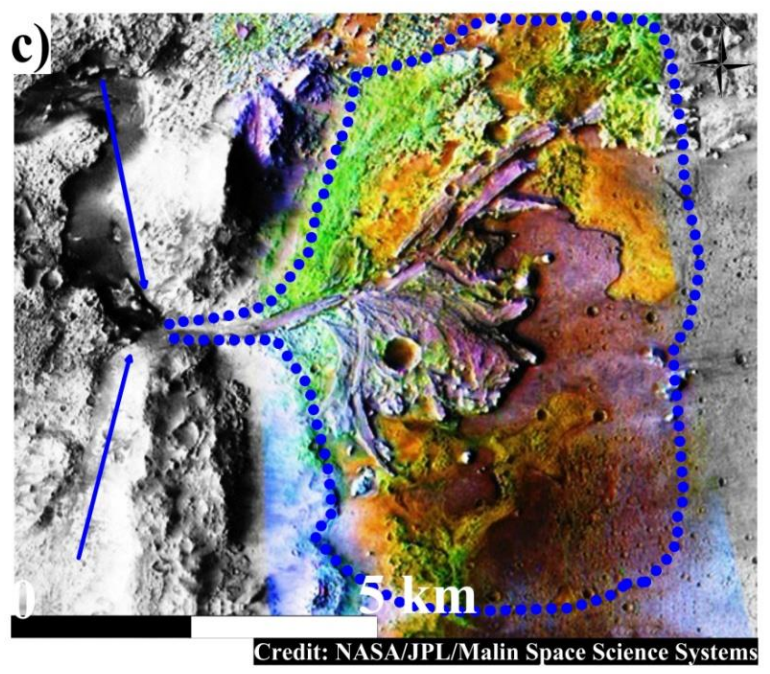

The western fan of Jazero delta

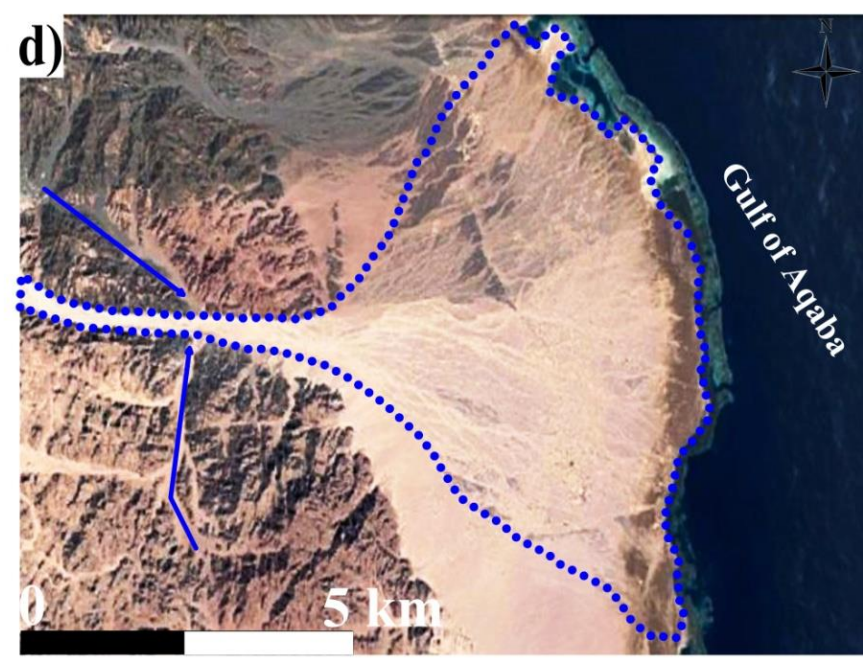

The alluvial fan of Wadi Kid basin, Sinai, Egypt

Fig. 9: (a) Digital terrain model (DTM) of the eastern portion of Mars' Valles Marineris (ESA/DLR/FU Berlin) represents the great rift in Mars. This rift is showing in comparison with (b) The Gulf of Suez rift, Egypt (Laak and Sheneshen, 2012). (c) The western fan of Jazero delta (located 18.9N, 77.5E). The colors are representing the different minerals where; Green: is phylosilicates, Yellow: is olivines, Blue/Purble: is pyroxenes, (Ehlmann et al., 2008). (d) Google Earth Tm showing the alluvial fan of Wadi Kid basin, Sinai Egypt. The dashed blue lines are representing the boundaries of the fans, while the solid blue arrows show the drainage (surface runoff directions) which feed the fan with water. The copyright note for these images and their interpretation: for image (9.a); the source is ESA with Credits: ESA/DLR/FU Berlin (G. Neukum), for image (9.c): Credit: NASA/JPL/Malin Space Science Systems 

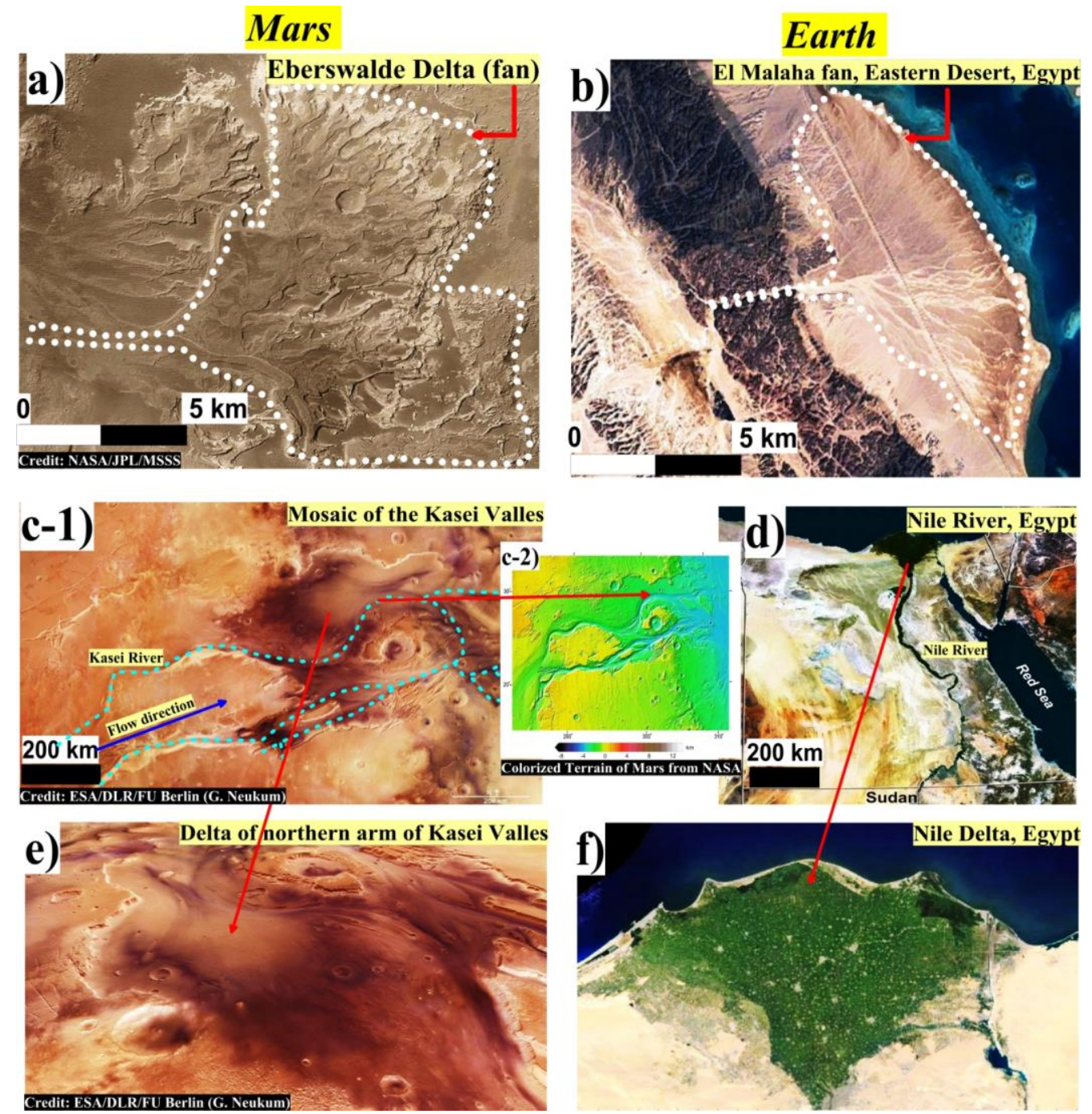

Fig. 10: Comparison between palaeohydrologic Features of Mars and their corresponding on Earth. a) Eberswalde Delta (fan) that was detected by Michael Malin and Kenneth Edgett from the Malin Space Science Systems where images were picked by the Mars Global Surveyor throughout 2003 and pointed out that this delta has 100 meters thick. b) El Malaha fan of Eastern Desert, Egypt that was formed through the water action in the pluvial time of Earth. c-1) Mosaic of the Kasei Valles shows the drainage network with flow direction to the east where the Colorized Terrain (c-2) illustrate the low elevations of the drainage lines (between 0 and $-4 \mathrm{~km}$ ). The Kasei Valles is compared with (d) the Nile valley of Egypt (Earth) and forming Nile Delta (f) in its downstream portion. The same feature is recorded at Mars (e) where the Kasei Valles forming its delta on the northern portion. The north direction for all images is to up. The copyright note for these images and their interpretation: for image (10.a); Source http://www.msss.com/mars_images/moc/2003/11/13 (author Jim Secosky modified NASA image) with Credits: NASA/JPL/MSSS, for images (10.c-1 and 10.e); Credits: ESA/DLR/FU Berlin (G. Neukum) and for image (10.c-2); the source is Colorized Terrain of Mars from NASA in Google Earth (author: Areong)

\section{Deltas of Mars}

The deltas are one of the most common palaeohydrologic features of Mars. Many deltas are discussed in the current study; such as the western fan of Jazero delta (Fig. 9c) and Eberswalde delta (Fig. 10), while the distribution of the potential deltas on Mars was mapped by Di Achille and Hynek (2010), (Fig. 11). The Jazero delta is covered by sediments composed of different minerals include; olivines, pyroxenes and phylosilicates, where it is thought to be formed during the past Mars wet history when this area was occupied by a lake (Ehlmann et al., 2008). The origin of these minerals maybe resulted from the erosion of the basement rocks (non-sedimentary rocks) or from the volcanoes lavas. Until now, no clear evidences if this delta is created through the action of water, ice or any other liquid. The same landform is recorded in Earth (Sinai, Egypt, Fig. 9d) where the two deltas (Jazero of Mars and Kid of Earth) are showing great similarity from the 
geomorphologic point of view. The same conditions were recorded through the image of Eberswalde delta (Fig. 10a, image was picked by the Mars Global Surveyor on 2003) where it was compared with El Malaha fan of Eastern Desert, Egypt that was formed through the water action in the pluvial time of Earth (Fig. 10b). On the other hand, the Kasei Valles (Fig. 10c-1) area shows a drainage network debouching to a delta (Fig, 10e) in its northern portion which characterized by low elevation values (Fig. 10c-2). These features of Kasei Valles are compared with the Nile River (Fig. 10d) of Egypt (Earth) that debouching to the Mediterranean Sea forming the
Nile delta (Fig. 10f) in its downstream portion. In general, many deltas (Fig. 11d) were mapped by Di Achille and Hynek (2010) and illustrated on a Mars Orbiter Laser Altimeter (MOLA) where these deltas are considered a distinguished landform which maybe resulted through water or any other liquid action. Therefore, the deposited sediments in these deltas are necessary to be sampled for detailed investigations. However, the distribution of the potential deltas (Fig. 11d) is associating with valleys networks that can strongly support believe that these landforms could be resulted from the precipitation during the past humid conditions.
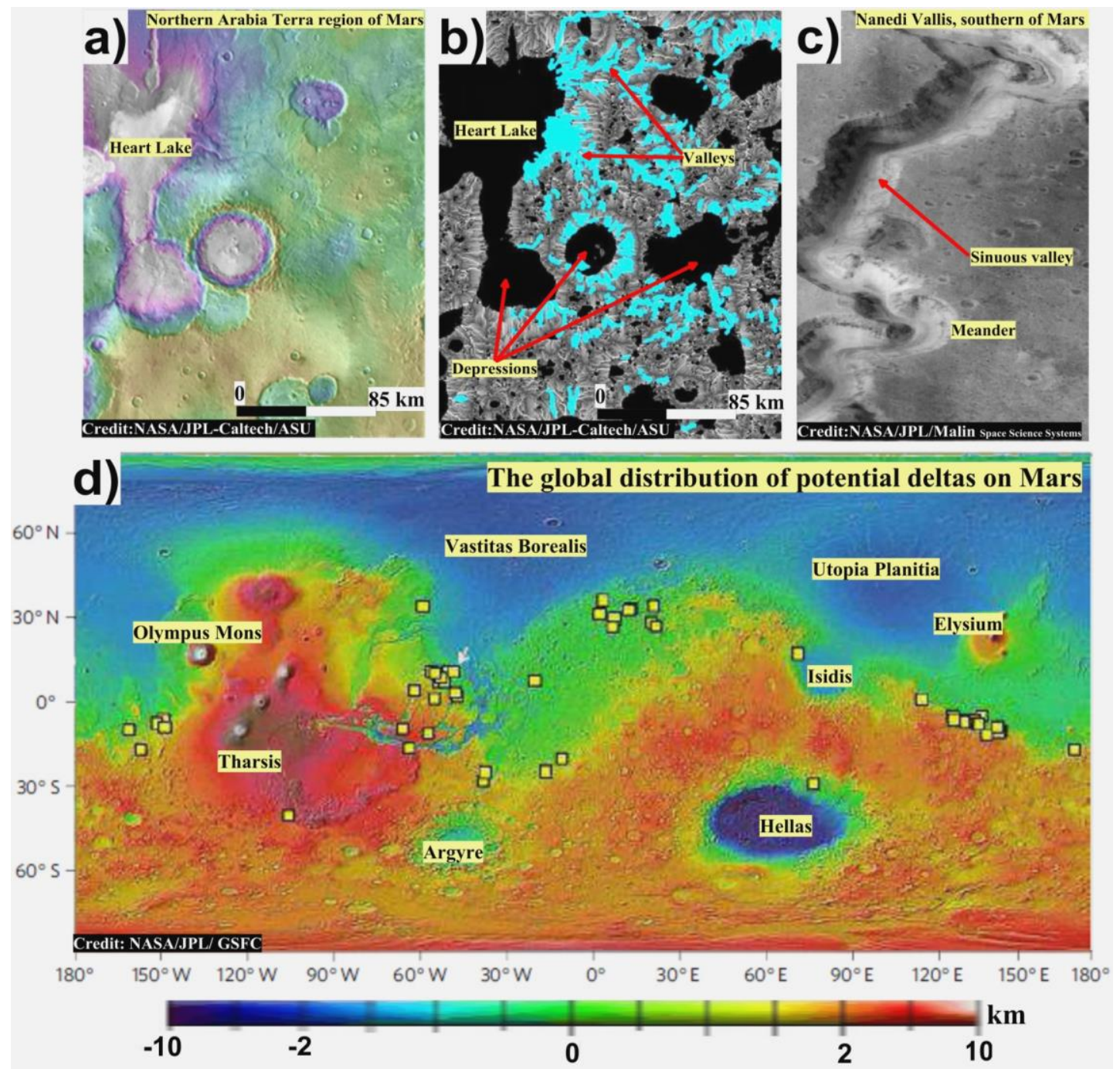

Fig. 11: Paleohydrologic features of Northern Arabia Terra and Nanedi Valles, as wells as potential deltas on Mars. (a) The Northern Arabia Terra region shows depressions (light pink color) forming a huge lake to the western north portion (a basin named; Heart lake). (b) The modeled of the Northern Arabia Terra (Wilson et al., 2016) region where; black color represents depressions and blue color represents water paths (valleys). (c) The internal channel over the floor of Nanedi Valles assumes that water flowed for a long time. (d) The global distribution of Mars potential deltas illustrated on a Mars Orbiter Laser Altimeter (MOLA) colorized elevation map (yellow boxes = locations of deltas). These deltas were mapped by Di Achille and Hynek (2010). The copyright note for these images and their interpretation: for image (11.a and 11. b); Credits: NASA/JPL-Caltech/ASU, for image (11.c); Credits: NASA/JPL/Malin Space Science Systems and for image (11.d); Credits: NASA/JPL/ GSFC 

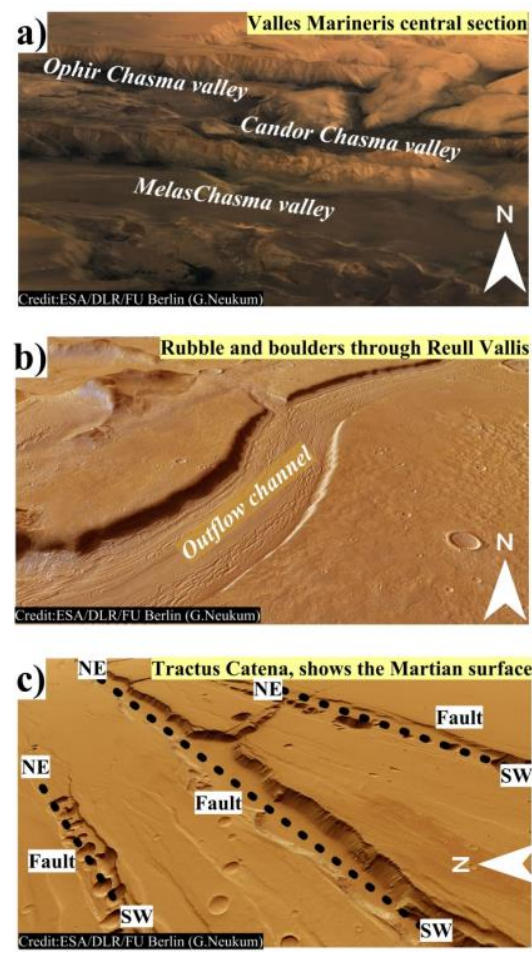
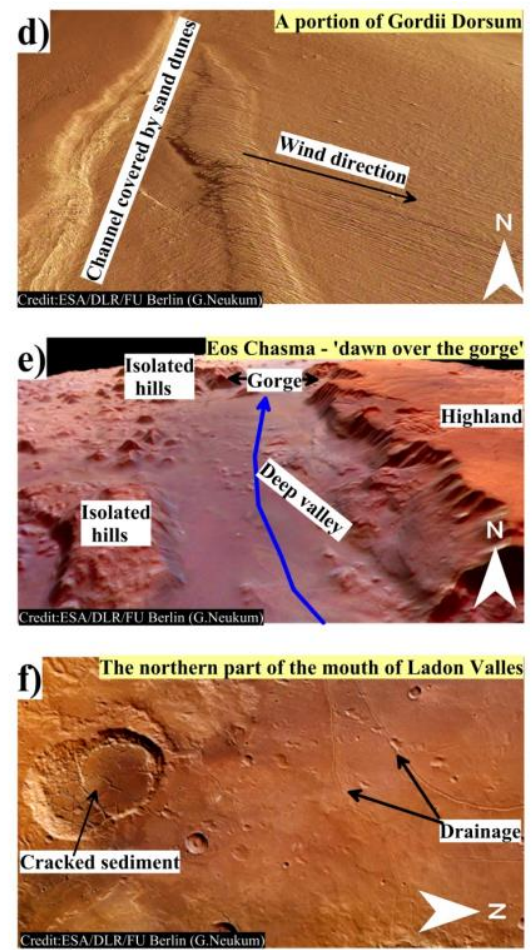
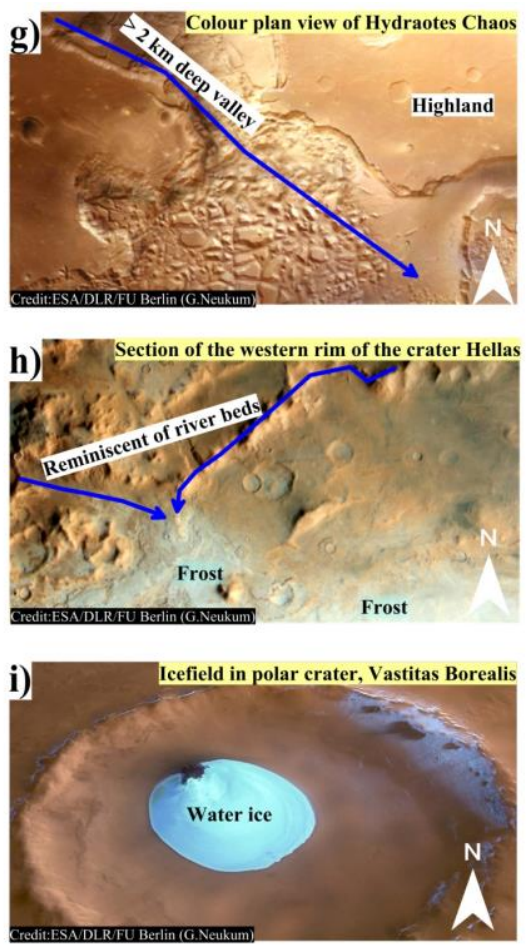

Fig. 12: (a) The central section of Valles Marineris looking from south to north. The image shows the three parallel valleys; Melas Chasma, Candor Chasma and Ophir Chasma, with about $200 \mathrm{~km}$ wide for each of the three mentioned valleys. (b) Rubble and boulder deposits in Reull Vallis where ice flows have deposited rubble and boulders in the upper section of outflow channel that has $7 \mathrm{~km}$ wide and $300 \mathrm{~m}$ deep. The image shows the pattern that was left after the ice mass melted; in which the glacier movement and its rocky cargo is obviously visible. (c) Tractus Catena perspective view of the Martian surface that was created through the data acquired by the stereo and color channels of (HRSC) on board ESA's Mars Express spacecraft. The image shows fractures of Tractus Catena, where multiple channels with $1500 \mathrm{~m}$ deep have formed along the fault lines. (d) Gordii Dorsum perspective view where a channel that was formed along the water path, is covered by sand dunes. (e) A perspective view of Eos Chasma shows the gorge along the main channel. The deep valley is passing through this gorge which acts as barrier and calms the water speed and flow rate. (f) Image of the northern part of the Ladon Valles (created by through data of High Resolution Stereo Camera (HRSC) on board ESA's Mars Express spacecraft). This image is covering about $22,500 \mathrm{~km}^{2}$, where water has left its paleohydrologic features such as; layers of sediment (located in the lower left portion) and the lowland areas (light white color) where deposits of minerals that were formed in water. (g) View image of Hydraotes Chaos shows $2 \mathrm{~km}$ deep valley resulted through the combination of geological structure, water action and erosion processes (it is thought that no comparable landforms are existed on Earth). (h) Image shows a section of the crater Hellas (the western rim) shows reminiscent of river beds, where ice flows moved downwards and transported (the lower areas are covered by frost). (i) Image view of the ice field in polar crater where water ice is located on the bottom of a crater (in the near portion of the Martian North Pole). The water ice is standing out clearly in the centre of the crater (with about $35 \mathrm{~km}$ across), where ice could remain in the centre of the crater during the year due to low temperature and low atmospheric pressure that prevent sublimation (transition from a solid state to a gaseous one). The copyright note for these images and their interpretation ("12a" to "12i"): As a joint undertaking by DLR, ESA and FU Berlin, the Mars Express HRSC images are published under a creative commons license since Dec. 2014 (ESA/DLR/FU Berlin, CC BY-SA 3.0 IGO). This license applies for the all of HRSC images released to this date (Credits: ESA/DLR/FU Berlin, CC BY-SA 3.0 IGO)

\section{Paleolakes, Paleochannels, Gorges and Sediments}

The paleohydrologic features of Northern Arabia Terra (Fig. 11a) shows many depressions representing lakes that assumed to be filled with water. The modeled of the paleolakes (Fig. 11b) in Northern Arabia Terra region (Wilson et al., 2016) was based on the equal elevation for the end and origin of the level of incoming and outgoing fresh shallow valleys at the modeled boundaries of the basins; as well as the inferred deltaic sediments existed in the model predicted lakes. This model provides morphological evidences about the valleys and lakes where the drainage started abruptly on uplands and terminates along the flanks of numerous depressions at elevations that correspond to paleolakes (Wilson et al., 2016). On the other hand, many paleochannels are recorded branching from the main valleys, such as the central section of Valles Marineris 
where three parallel channels; Melas Chasma, Candor Chasma and Ophir Chasma, are existed with about 200 $\mathrm{km}$ wide for each one (Fig. 12a). Also, the image of Reull Vallis shows outflow channel that was resulted through ice flows and left a pattern after the ice mass melted (Fig. 12b). In Tractus Catena of the Martian surface, multiple channels with $1500 \mathrm{~m}$ deep have formed along the faults (Fig. 12c), while in Gordii Dorsum a channel that was formed along the water path and covered by sand dunes (Fig. 12d). On the Earth, the gorges can be considered as one of the palaeohydrologic features that indicates the action of surface water across narrow fractures. A gorge is identified in Eos Chasma where the image shows the gorge along the main channel and acts as barrier and calms the water speed and flow rate (Fig. 12e). However, some sedimentary structures are recorded from the satellite images indicate the wetter climate, such as the existence of cracked sediments of the northern part of the Ladon Valles (Fig. 12f). Consequently, some hydrogeomorphologic features are appearing on Mars that are thought to be resulted from both influences of geologic structures and surface water such as; the case of Hydraotes Chaos (Fig. 12g) where it is thought that a deep valley was originated through association of geological structure, surface runoff and erosion processes and the crater Hellas where ice flows moved downwards and transported (Fig. 12h).

\section{Discussion}

\section{The Palaeohydrologic Regime of Mars}

The hydrogeomorphology of Mars planet suggests past wetter conditions where the transition from wet to dry surface conditions is evidenced through a variations in the spatial distribution of drainage networks. The ancient fluvial features of Mars provide evidences about the past periods of hydrologic activities and the prevailed paleoclimate conditions which were suitable for liquid water (Jacobsen, 2016). These widespread drainage networks that are extending to regional drainage divides can suggest a climatic source for fluvial runoff (Hynek and Phillips, 2003; Howard et al., 2005). The obtained results through the insight from satellite images suggesting that the drainage networks of Mars can be originated through past precipitation or ice melting. However, the dendritic drainage type was resulted from the paleo-precipitations. This assumption is based on the comparison between the both landforms on Mars and Earth. The geologic history of the drainage formation reveals that the wet climate prevailed upon the Mars planet since about $3.7 \mathrm{Ga}$. The younger craters are dissecting the drainage networks where the size and frequency distributions of those craters suggest that networks were formed around the geologic border between Noachian and Hesperian Epochs, since $\sim 3.7 \mathrm{Ga}$ (Howard et al., 2005; Fassett and
Head, 2008). Then, after this time, the surface hydrology started to change as is approved by a decrease in the number, size and geospatial distribution of the drainage networks throughout Late Hesperian and Early Amazonian; since $\sim 3.0 \mathrm{Ga}$ (Fassett and Head, 2008; Hynek et al., 2010). In the current study, many landforms are recorded through the satellite images include; drainage networks, deltas (fans), paleolakes, paleochannels, gorges and sediments. These landforms can provide evidences about the palaeohydrologic regime of Mars where they indicate the past wetter conditions. This is compatible with the works of Howard et al., 2005; Fassett and Head, 2008; Carr, 2012; Goudge et al., 2016, where they stated that valley networks, outflow channels, lakes, degraded crater rims and sedimentary fans are representing the global influences of a waning hydrologic system of the Mars. Also, Jacobsen (2016) investigated the Aeolis Dorsa region where his results include assemblages of fluvial features indicate a wet to dry hydrologic transition. This past transition of hydrologic activities was preserved in drainage networks and alluvial fans on Mars. The obtained structural lineaments show main trend as NE-SW (Fig. 4) where these lineaments are thought to be responsible with erosion processes about the origination of the drainage network of Mars. These conditions are the same like Earth where the drainages were initiated during the past pluvial times through the actions of surface runoff along fractures and/or faults (Figs. 7d, 9d, 10b). Indeed, the available data is mainly depending on the investigation of satellite images, where the samples are so limited till now. Therefore, the current study is based on the real data which extracted from the satellite images. This data includes the landforms where their shapes and distributions can reflect the palaeohydrogic regime of Mars. It can be believed that the selected landforms in this study (Figs. 5 to 12), are revealing an ancient wet climates where precipitation was leading to surface runoff with main role of the tectonic influences existed on structural lineaments and rifts (Figs. 4 and 5).

\section{Hydrogeomorphology of Mars Versus Earth (Egypt)}

The hydrogeomorphological features of the Egyptian deserts are chosen as inferences for the existed landforms on the surface of Mars. Here, the hydrogeomorphologic features are mean the landforms that were resulted throughout the past hydrologic cycle prevailed Earth or Mars. The recorded landforms of Egypt are showing similarity with the existed one of Mars. These landforms are investigated through field investigation and through the satellite images where they are confirming this similarity. The investigation of the drainage network (Fig. 6g) along the edge of Sin El Kadab plateau (one of the most important tableland in the Western Desert of Egypt) reveals that these networks were initiated during 
the pluvial times where the humid climate was prevailed (Yousif et al., 2018; Yousif, 2019). Also, this type of drainage maybe resulted from groundwater sapping where water was flowing to the surface and lead to the formation of these drainages (Abotalib et al., 2016; 2019). This hypothesis can be applied for the drainage networks of the Kaiser crater as appear in image (Fig. 6f) which need more future investigation. On the other hand, the dendritic drainage (Fig. 7d) of Wadi Qena (one of the mega basins in the Eastern Desert of Egypt) is resulted through the action of both geological structures and erosion processes by surface runoff. This type is the most corresponding to the recorded drainage at the east of Huygens crater (Fig. 7a) which assumed to be clear evidence about the past humid climate of Mars. In addition, one of the most distinguished landform on Mars is Olympus Mons which represents the largest volcano in our solar system. It located with other two volcanoes with a trend NE-SW (Fig. 8b) which is very similar to basaltic volcanism flow in Sinai (Egypt, Earth), (Fig. 8d). The most common landform is the delta where many are observed on Mars similar to those which recorded in the Egyptian Desert (review Figs. 9c and 9d; Figs. 10a-10d). Consequently, sediments and sedimentary structures associated with the existed landforms in both of Mars and Earth are also showing some similarity. The photograph of the strata rocks and fractured sandstone of Kimberley area in Mount Sharp of Mars (Fig. 13a) are compatible with the photo of fractured sandstone on the floor of El Kubanyia basin (western Desert, Egypt, Earth), (Fig. 13b). The investigated conditions of this Earth photo indicate that the flow direction of surface water is toward a low elevated basin passing by fractured sandstone representing the bed rock in the basin. These conditions can be assumed also for Kimberley area on Mars depending on the existed landforms where the sediments still need more investigation. Finally, from the hydrogeomorphologic point of view, the landforms of Mars (Figs. 13c, 13e and 13g) can be subdivided like the Earth (Figs. 13d, 13f and 13h) to: Highlands which represent watersheds (such as; plateaus, mountains, volcanoes,.. etc.) and lowlands that correspond to water collectors (such as; drainage networks, lakes, basins.. etc.). In my view point, the past water behavior and distribution on Mars planet are still the most exciting questions. However, the mentioned questions are motivated by geomorphologic evidences such as aforementioned palaeohydrologic landforms (in the current study) that have been investigated to mean that liquid water may have been existed periodically on Mars during the past periods (Carr, 1996). Unfortunately, the multiplicity of current theories regarding the past history of water on Mars point out some of the difficulties in attempting to understand the past purely from an incompletely observed martian geologic record (NAS, 2003). For example, oceans do not just spring out of nowhere: If there were large oceans at some point in Mars's history, there must also have been certain definable environmental conditions that enabled their stability. Therefore, detailed models for the Mars atmospheric circulation are existed and improved (Haberle et al., 1993). They are matching with the atmosphere observations obtained through the Mars Global Surveyor (MGS, 2004; 2013) which is reasonably well (Leovy, 2001).

\section{Future Exploration and Landing on Mars}

The Mars planet is still a source of wonder for many issues regarding the existence of life which consequently related to the presence of water. The ESA (2019, Robotic exploration of mars) reported that more than 40 missions have been travelled to the Mars since 1960, where they attempted to characterize and provide information about Mars These missions were followed by orbiters, which conveyed perpetually sophisticated instruments to outline the whole planet and describe its landforms. The reported $1^{\text {st }}$ fully successful touchdowns above the surface of Mars was achieved through US Viking 1and 2 lander (on 1976), followed by five more successful landings as well as a number of failed attempts (Fig. 14a). Accordingly, the suggestion of potential landing sites should be based on some criteria such as; nature and safety of the terrain, existence of evidences that support surface water existence and potentially habitable environments (NASA, 2020, Mars Mission).

The current study suggests two landing sites for the next Mars 2020 mission taking in consideration the mentioned criteria by NASA. Therefore, two sites (Fig. 14a) from the investigated locations from the palaeohydrologic viewpoint in this study are proposed for the next missions, they are: (1) The fan of Jazero delta that located on 18.9N, 77.5E, (L1_2020, Fig. 14b), (Fig. 9c) and (2) Eberswalde Delta (Fig. 10a), (L2_2020, Fig. 14c). According to NASA (2020, Mars Mission), the site of landing should has high potential of considerable water resources that may be use for future investigation whatever in the form of water-rich hydrated minerals, ice regolith or subsurface ice. Consequently, the two proposed sites are selected from the different observed regions of this study where they show low elevations and have indications for water occurrences. The Jezero delta (L1_2020, Fig. 14b) shows different minerals which are thought to be transferred by surface water from the upstream area though drainage or channels. Therefore, possibly, microbial lives life could have existed in Jezero during at least one of the past wet occasions. If that is true, indications and signs of their remaining parts may be found in lakebed deposits. Also, Eberswalde delta (L2_2020, Fig. 14c) which represents a large fan-shaped structure is proposed for landing where this area shows ancient distinguished delta. 

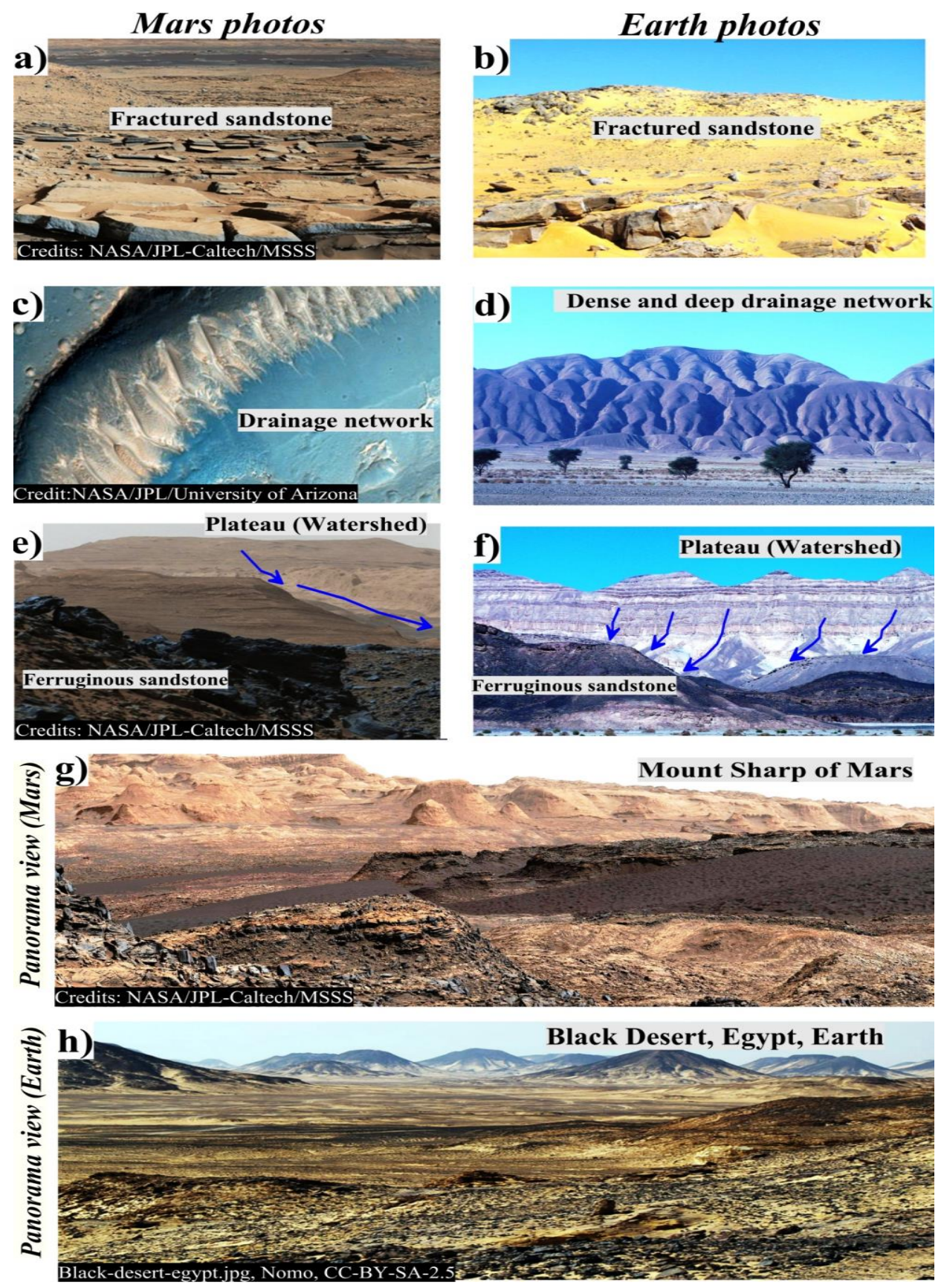

Fig. 13: Photos and images for palaeohydrologic features of Mars compared to Earth-compatible features (a) Photo of strata rocks and fractured sandstone of Kimberley area in the base of Mount Sharp. The strata indicate the flow direction of water toward a basin which existed before the huge bulk of the mountain formed. (b) Fractured sandstone on the floor of El Kubanyia valley, western Desert, Egypt, Earth. (c) Image of valley along Noctis Labyrinthus floor shows the dense drainage networks. (d) Dense and deep drainage network of Gebel Duwi, Eastern Desert, Egypt, Earth. (e) Dark rocks on route to Mount Sharp mountains that maybe affected by hydrothermal solution that come out of volcano. (f) Back view of Gebel Duwi where the sandstone affected by hydrothermal solution in the vicinities of this mountain, Eastern Desert, Egypt, Earth. (g) Panorama view of the area lining along the northwestern edge of Mount Sharp shows the watersheds where the drainage lines were originated. The rocks are thought to be affected with hydrothermal solutions or any intrusions from the volcanoes. (h) Black desert of Egypt, Earth, the image shows manifestations maybe like to those recorded on Mars. The copyright note for these images and their interpretation: for image (13.a); the images obtained by NASA's Curiosity rover in October, 2015, with Credits: NASA/JPL-Caltech/MSSS, for image (13.c); the Credits: NASA/JPL/University of Arizona and for images (13.e and 13.g), Credits: NASA/JPL-Caltech/MSSS 

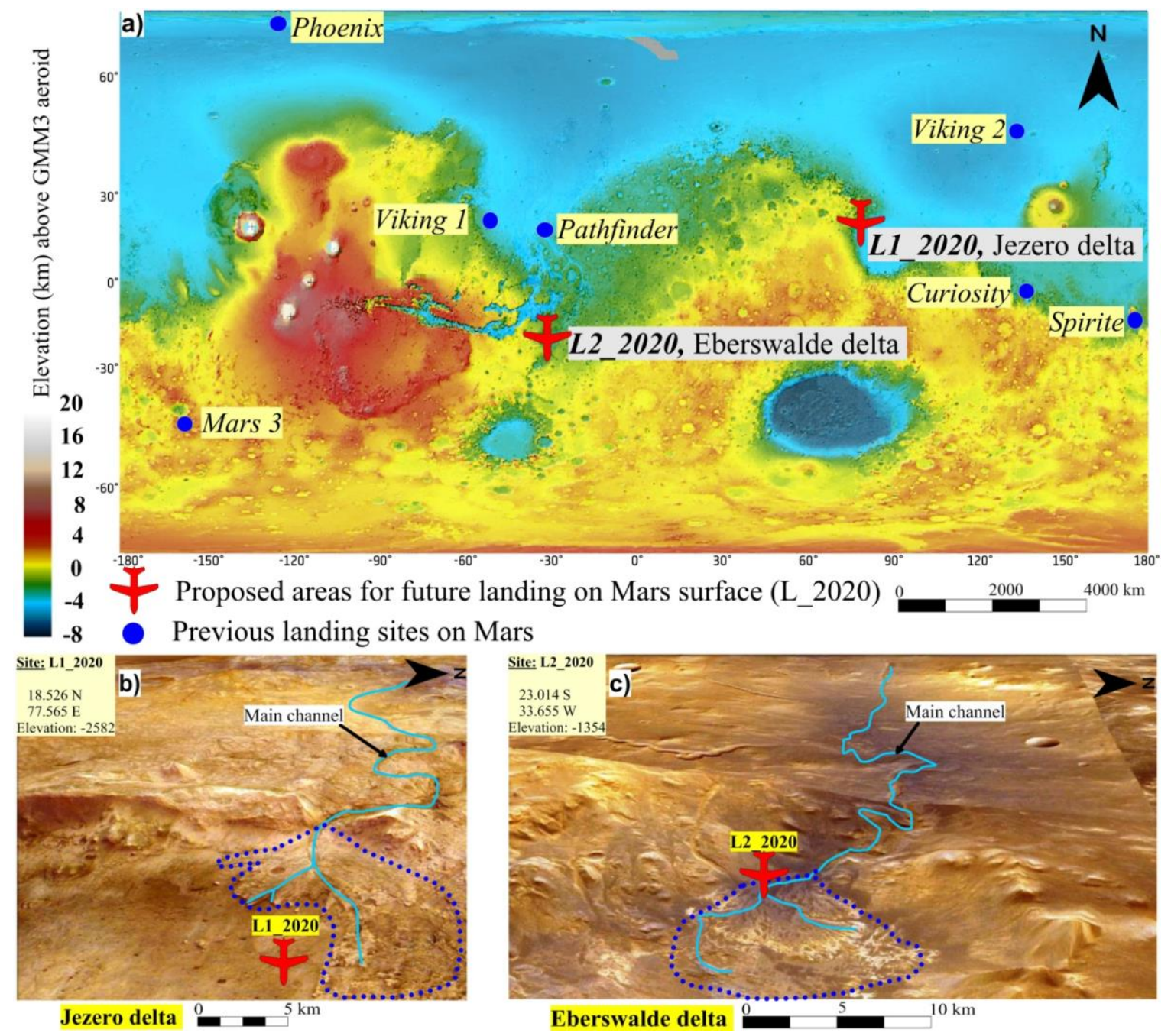

Fig. 14: Proposed sites for future landing on Mars. (a) The previous landing sites map of the rovers and landers that have successfully touched down the Mars (sites by NASA, 2016). The two proposed sites (L1 and L2, 2020) are illustrated on the same background image (Multi-orbit digital terrain models (DTM) derived from multiple stereo image strips of the HighResolution Stereo Camera (HRSC) of ESA's Mars Express, available at: HRCS web GIS, FUB/DLR/ESA). (b) Map of the first site (L1_2020) showing the Jezero delta illustrated on a three dimensional view of Google Mars Tm image. (c) Map of the second site (L2_2020) showing the Eberswalde delta illustrated on a three dimensional view of Google Mars Tm image.The copyright note for the background images (14a, 14b and 14c) is: Credits: ESA/DLR/FU Berlin (G. Neukum)

This delta has 100 meters thick that was detected by Michael Malin and Kenneth Edgett from the Malin Space Science Systems by the Mars Global Surveyor throughout 2003 (MGS, 2004). The landform of these two sites is compared with the similar on Earth from the morphologic point of view. The two proposed sites that are representing deltas on Mars reveal a humid palaeohydrologic regime where these places are thought to be subjected to existence of water for long period's time. Also, the reported drainage networks debouching to these two deltas are clear from the satellite images that indicate the directions of surface runoff and sediments transportations. Finally, the deep groundwater on Mars (theoretical penetration depth $\sim 500 \mathrm{~m}$ ) of orbital sounding radar sensors (Abotalib and Heggy, 2019) should be subjected to more investigations through the next missions to clarify the its occurrence and recharge processes. These sites should be subjected to more investigations through NASA and ESA to evaluate their potentialities for landing during next mission.

\section{Conclusion}

In this study, the main attention is paid to the landforms that could be originated through the surface water action during any possible past humid climate prevailed the Mars planet. Indeed, the available data is mainly depending on the investigation of high resolution 
satellite images, where the samples are so limited till now. Therefore, the current study is based on the real data which extracted from the satellite images. This data includes the landforms (drainages, deltas, gorges, paleolakes, paleo-channel) where their shapes and distributions can reflect the palaeohydrogic regime of Mars. The hydrogeomorphology of Mars planet suggests past wetter conditions where the transition from wet to dry surface conditions is evidenced through a variations in the spatial distribution of drainage networks. The ancient fluvial features of Mars provide evidences about the past periods of hydrologic activities and the prevailed paleoclimate conditions which were suitable for liquid water. The obtained structural lineaments show main trend as NE-SW where these lineaments are thought to be responsible with erosion processes about the origination of the drainage network of Mars. These conditions are the same like Earth where the drainages were initiated during the past pluvial times through the actions of surface runoff along fractures and/or faults. The Mars planet is still a source of wonder for many issues regarding the existence of life which consequently related to the presence of water. From the palaeohydrologic viewpoint, the study suggests two proposed sites for the next missions; The Jazero delta and the Eberswalde. These deltas are showing possibilities for existence of water resources that may be use for future investigation whatever in the form of water-rich hydrated minerals, ice regolith or subsurface ice. Consequently, the two proposed sites are selected from the different observed regions of this study where they show low elevations and have indications for water occurrences. Finally, this study is representing a testing approach to employ the hydrogeomorphologic setting and landforms investigation to elucidate the palaeohydrologic regime of Mars with inferences from the same features of the Earth.

\section{Funding}

This research did not receive any specific grant from funding agencies in the public, commercial, or not-forprofit sectors

\section{Availability of Data and Material}

All data generated or analyzed during this study are included in this manuscript.

\section{Acknowledgement}

The author is grateful to DLR (Deutsches Zentrum für Luft- und Raumfahrt "German Aerospace Center") and ESA (the European Space Agency) for providing the satellite images of Mars through the Mars Express gallery on their websites. Many thanks for Dr. Abotalib
Z. Abotalib (Western Michigan University, USA) for his advice during the preparation of this manuscript. The author is appreciating to Professor Dr. Moustafa El Ghazawy and Professor Dr. Mohamed Abbas Mabrouk for their valuable advices, scientific discussions and continues support during the work of this manuscript. Many thanks with sincere prayers for who encouraged me to carry out this research.

\section{References}

Abotalib, A.Z., M. Sultan and R. Elkadiri, 2016.Groundwater processes in Saharan Africa: Implications for landscape evolution in arid environments. Earth-Sci. Rev., 156: 108-136.

Abotalib, A.Z., M. Sultan, G. Jimenez, L. Crossey and K. Karlstrom et al., 2019. Complexity of Saharan paleoclimate reconstruction and implications for modern human migration. Earth Planet. Sci. Lett., 508: 74-84. DOI: 10.1016/j.epsl.2018.12.015

Abotalib, Z.A. and E. Heggy, 2019. A deep groundwater origin for recurring slopelineae on Mars. Nature Geosci., 12: 235-241.

Bibring, J.P., Y. Langevin, F. Poulet, A. Gendrin and B. Gondet et al., 2004. Perennial water ice identified in the south polar cap of mars. Nature, 428: 627-630.

Bosworth, W., 2015. Geological Evolution of the Red Sea: Historical Background, Review and Synthesis. In: The Red Sea, Rasul, N. and I. Stewart (Eds.), Springer Earth System Sciences, pp: 45-78.

Brandenburg, J.E., 1987. The paleo-ocean of mars. Proceedings of the MECA Symposium on Mars: Evolution of its Climate and Atmosphere, Jul. 17-19, Lunar and Planetary Institute, Houston, pp: 20-22.

Burr, D.M., R.M.E. Williams, K.D. Wendell, M. Chojnacki and J.P. Emery, 2010. Inverted fluvial features in the Aeolis/Zephyria Plana region, Mars: Formation mechanism and initial paleodischarge estimates. J. Geophys. Res. Planets, 115: E07011-E07011. DOI: 10.1029/2009JE003496

Carr, M.H., 1996. Water on Mars. 1st Edn., Oxford University Press, New York, ISBN10: 0195099389, pp: 229.

Carr, M.H., 2012. The fluvial history of Mars. Philosophical Trans. Royal Society London A: Math. Phys. Eng. Sci., 370: 2193-2215. DOI: $10.1098 /$ rsta.2011.0500.

Christensen, P.R., 2006. Water at the poles and in permafrost regions of mars. GeoScience World Elements, 3: 151-155.

CRISM, 2019. Compact Reconnaissance Imaging Spectrometer for Mars. Earth/Mars Comparison of Geological Features, Guide Lesson.

Di Achille, G. and B.M. Hynek, 2010. Ancient ocean on Mars supported by global distribution of deltas and valleys. Nature Geosci., 3: 459-463. 
Ehlmann, B.L., J.F. Mustard, C.I. Fassett, S.C. Schon and J.W. Head III et al., 2008. Clay minerals in delta deposits and organic preservation potential on Mars. Nature Geosci., 1: 355-358.

ESA, 2019. Robotic exploration of Mars. European Space Agency.

ESA, 2004. Water at Martian south pole. European Space Agency.

Fassett, C.I. and J.W. Head III, 2008. Valley networkfed, open-basin lakes on Mars: Distribution and implications for Noachian surface and subsurface hydrology. Icarus, 198: 37-56.

DOI: 10.1016/j.icarus.2008.06.016

Goudge, T.A., C.I. Fassett, J.W. Head, J.F. Mustard and K.L. Aureli, 2016. Insights into surface runoff on early Mars from paleolake basin morphology and stratigraphy. Geology, 44: G37734.1-G37734.1. DOI: $10.1130 / G 37734.1$

Greeley, R. and J. Guest, 1987. US Geology Surv. Misc. Invest. Ser., Map I-1802-B 1, 15.

Haberle, R.M., H.C. Houben and R.E. Young, 1993. Multiannual simulations with the mars climate model. Proceedings of the International Workshop on Atmospheric Transport on Mars, (ATM' 93), Lunar and Planetary Institute, Houston, Texas, pp: 14-14.

Hamilton, W.B., 2007. Geological Society of America Memoirs.

Hartmann, W. and G. Neukum, 2001. Cratering chronology and the evolution of Mars. Space Sci. Rev., 96: 165-194. DOI: 10.1023/A:1011945222010

Hauber, E., M. Grott and P. Kronberg, 2010. Martian rifts: Structural geology and geophysics. Earth Planetary Sci. Lett., 294: 393-410.

Hoke, M.R.T., B.M. Hynek, G. Di Achille and E.W. Hutton, 2014. The effects of sediment supply and concentrations on the formation timescale of Martian deltas. Icarus, 228: 1-12.

DOI: 10.1016/j.icarus.2013.09.017

Howard, A.D., J.M. Moore and R.P. Irwin III, 2005. An intense terminal epoch of widespread fluvial activity on early Mars: 1. Valley network incision and associated deposits. J. Geophys. Res., 110: E12S14-E12S14. DOI: 10.1029/2005JE002459

Howard, A.D., 2007. Simulating the development of Martian highland landscapes through the interaction of impact cratering, fluvial erosion, and variable hydrologic forcing. Geomorphology, 91: 332-363. DOI: 10.1016/j.geomorph.2007.04.017

Hynek, B.M. and R.J. Phillips, 2003. New data reveal mature, integrated drainage systems on Mars indicative of past precipitation. Geology, 31: 757-760. DOI: $10.1130 / G 19607.1$
Hynek, B.M., M. Beach and M.R.T. Hoke, 2010. Updated global map of Martian valley networks and implications for climate and hydrologic processes. J. Geophys. Res.: Planets, 115: E09008-E09008. DOI: 10.1029/2009JE003548

Irwin, III, R.P., R.A. Craddock and A.D. Howard, 2005. Interior channels in Martian valley networks: Discharge and runoff production. Geology, 33: 489-492. DOI: 10.1130/G21333.1

Jacobsen, R.E. and D.M. Burr, 2016. Greater contrast in Martian hydrological history from more accurate estimates of paleodischarge. Geophys. Res. Lett., 43: 8903-8911. DOI: 10.1002/2016GL070535

Jacobsen, R.E., 2016. Geomorphology, stratigraphy and paleohydrology of the Aeolis Dorsa region, Mars, with insights from modern and ancient terrestrial analogs. PhD. Thesis, University of Tennessee.

Jacobsen, R.E. and D.M. Burr, 2018. Errors in Martian paleodischarges skew interpretations of hydrologic history: Case study of the Aeolis Dorsa, Mars, with insights from the Quinn River, NV. Icarus, 302: 407-417. DOI: 0.1016/j.icarus.2017.11.014

Jakosky, B.M. and R.M. Haberle, 1992. The Seasonal Behavior of Water on Mars. In: Mars, Kieffer, H.H., B.M. Jakosky, C.W. Snyder and M.S. Matthews (Eds.), University of Arizona Press, Tucson, AZ, pp: 969-1016.

Kite, E.S., A.D. Howard, A.S. Lucas, J.C. Armstrong and O. Aharonson et al., 2015. Stratigraphy of Aeolis Dorsa, Mars: Stratigraphic context of the great river deposits. Icarus, 253: 223-242.

DOI: $10.1016 /$ j.icarus.2015.03.007

Laak, A. and M. Sheneshen, 2012. Integrated fault mapping in gulf of Suez Rift Zone. Proceedings of the 10th Middle East Geosciences Conference and Exhibition, Mar. 4-7, Manama, Bahrain.

Leovy, C., 2001. Weather and climate on Mars. Nature, 412: 245-249.

MGS, 2004. Mars global surveyor orbital information Aerobraking orbit elements. mars.jpl.nasa.gov (Technical report).

MGS, 2013. Mars global surveyor orbital information aerobraking orbit elements. Science Objectives, NASA, JPL.

Mittlefehldt, D.W., 1994. ALH84001, a cumulate orthopyroxenite member of the martian meteorite clan. Meteoritics, 29: 214-221.

DOI: 10.1111/j.1945-5100.1994.tb00673.x

NAS, 2003. Assessment of Mars science and mission priorities. Space Studies Board.

NASA, 2020. MARS mission, science evaluation criteria for the Mars 2020 Landing Site. 
Rossi, A.P. and S. vam Gasselt, 2010. Geology of Mars after the first 40 years of exploration. Res. Astronomy Astrophys., 10: 621-652.

Scott, D.H. and M.H. Carr, 1978. Geologic map of Mars, I-1083. U.S. Geological Survey, Reston.

Scott, D. and K. Tanaka, 1986. US Geol. Surv. Misc. Invest. Ser., Map I-1802-A.

Tanaka, K.L., D.H. Scott and R. Greeley, 1992. Global Stratigraphy. In: Mars, Kieffer, H.H., B.M. Jakosky, C.W. Snyder and M.S. Matthews (Ed.), University of Arizona Press, pp: 345-382.

Tanaka, K.L., 1986. The stratigraphy of Mars. J. Geophys. Res., 91: E139-E158.

DOI: $10.1029 / J B 091 i B 13 p 0 E 139$

Wilson, S.A., A.D. Howard, J.M. Moore and J.A. Grant, 2016. A cold-wet middle-latitude environment on Mars during the Hesperian-Amazonian transition: Evidence from northern Arabia valleys and paleolakes. J. Geophys. Res., 121: 1667-1694.

Yousif, M., F. Henselowsky and O. Bubenzer, 2018. Palaeohydrology and its impact on groundwater in arid environments: Gebel Duwi and its vicinities, Eastern Desert, Egypt. CATENA, 17: 29-43.

DOI: $10.1016 /$ j.catena.2018.06.028

Yousif, M., 2019. Hydrogeological inferences from remote sensing data and geoinformatic applications to assess the groundwater conditions: El-Kubanyia basin, Western Desert, Egypt. J. African Earth Sci., 152: $197-214$.

DOI: 10.1016/j.jafrearsci.2019.02.003

\section{List of Abbreviations}

HiRISE: High Resolution Imaging Science Experiment MOLA: Mars Orbiter Laser Altimeter

MRO: Mars Reconnaissance Orbiter

DTM: Digital Terrain Model

NASA: National Aeronautics and Space Administration

DLR: Deutsches Zentrum für Luft- und Raumfahrt

ESA: The European Space Agency

MGS: Mars Global Surveyor

NAS: The National Academy of Sciences

HM: Hartmann model

NM: Neukum model

Ga: Giga-annum (one billion years)

Gyr: Giga years ago 